Portland State University

PDXScholar

$5-18-1977$

\title{
The Influence of Age and Stimuli on the Explanations of "Same" and "Different" by Young Children
}

Pamela Callas Senders

Portland State University

Follow this and additional works at: https://pdxscholar.library.pdx.edu/open_access_etds

Part of the Social and Behavioral Sciences Commons

Let us know how access to this document benefits you.

\section{Recommended Citation}

Senders, Pamela Callas, "The Influence of Age and Stimuli on the Explanations of "Same" and "Different" by Young Children" (1977). Dissertations and Theses. Paper 2604.

https://doi.org/10.15760/etd.2601

This Thesis is brought to you for free and open access. It has been accepted for inclusion in Dissertations and Theses by an authorized administrator of PDXScholar. Please contact us if we can make this document more accessible: pdxscholar@pdx.edu. 
AN ABSTRACT OF THE THESIS OF Pamela Callas senders for the Master of Science in Speech Communication: Fmphasis in Speech Pathology/Audiology presented May 18, 1977.

Title: The Influence of Age and Stimuli on the Explanations of "Same" and "Different" by Young Children.

APPROVED EY MEMBERS OF THE THESIS COMMITTEE:

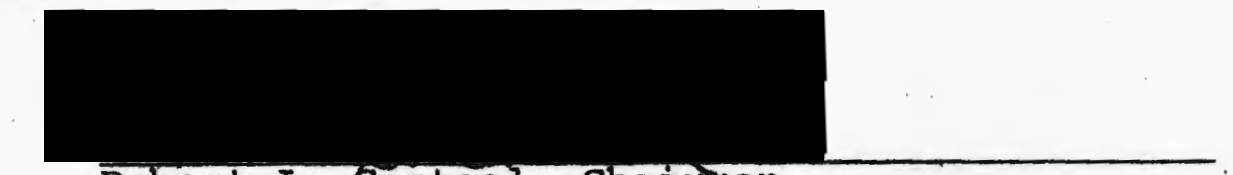

Robert L. Casteel, Chairman

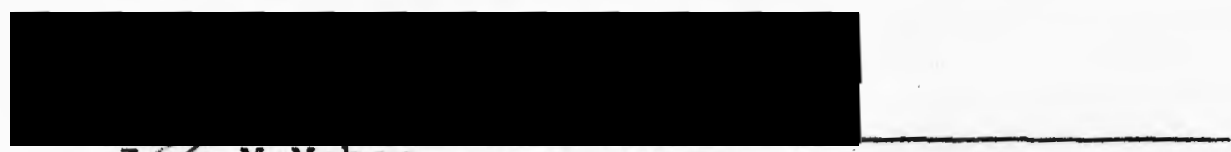

Joan McMahon

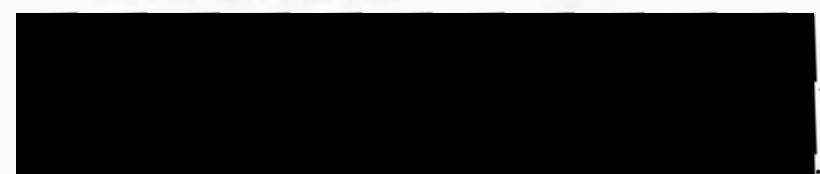

Gerald Guthrie

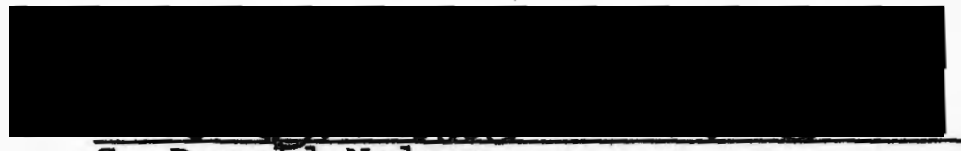

C. Donala Nelson

This study investigated the influence of chronological age and stimuli on the explanations of "same" and "different" by young children. Seventy children, between the ages of three-years, six-months and nine-years, six-months, selected on the basis of chronological age, normal speech and language 
development, and normal verbal maturity, were involved as subjects. A test consisting of a series of verbal tasks was administered to each child. The experimenter recorded and later analyzed and classified all responses for each child, following specific guidelines for judging appropriateness of response and assigning each appropriate response to one of three classifications.

The results of this study revealed that by six-years, six-months most children were able to explain both similarities and differences appropriately. Contrary to previous reports, this study revealed no significant differences between performance on explanations of similarities and explanations of differences. This may have been due in part to the fact that in this study item pairs were carefully selected to be the "same" or "different" with respect to at least three dimensions. No significant effect was revealed by a change in the three stimulus types used in this study. This absence of effect supported the argument that the opportunity to select the items to be compared was a more significant factor than a change in stimulus type.

There was a significant increase in mean number of appropriate responses per item up to six-years, six-months. The most frequent response type across all ages was Type IIFunction. The frequency of Type III-Nominal responses increased with age and remained lower than both Type IPerceptible and Type II-Function responses. The frequency 
of Type III responses increased much faster in explanations of similarity than in explanations of difference. Overall, the distributions of the three response types was consistent among the three stimulus types. The results suggest that rather than there being a consistent change with age in the frequency of specific response types, there is an increase in the variety of different response types with age. 
THE INFLUENCE OF AGE AND STIMULI ON THE EXPLANATIONS OF "SAME" AND "DIFFERENT". BY YOUNG CHILDREN

by

PAMELA CALLAS SENDERS

A thesis submitted in partial fulfillment of the requirements for the degree of

MASTER OF SCIENCE

in

SPEECH COMMUNICATION:

EMPHASIS IN SPEECH PATHOLOGY/AUDIOLOGY

Portland State University

1977 
TO TIE OFFICE OF GRADUATE STUDIES AND RESFARCH:

The members of the committee approve the thesis of Pamela Callas Senders presented May 18, 1977.

Robert I. Casteel, Chairman

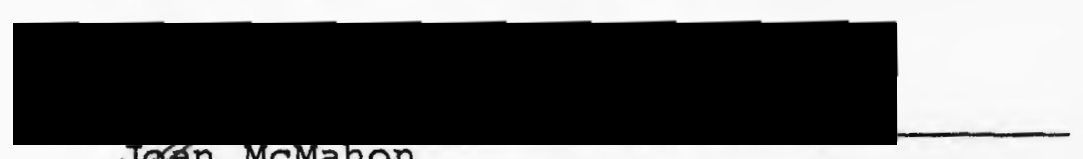

Joan McMahon

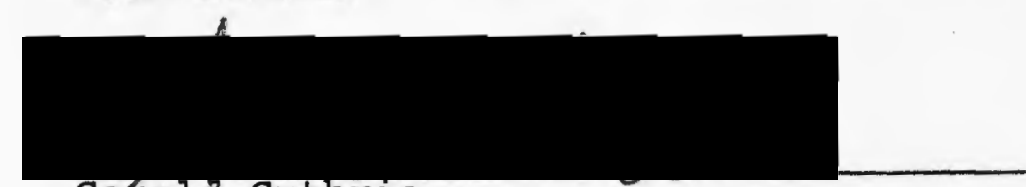

Gerald Guthrie

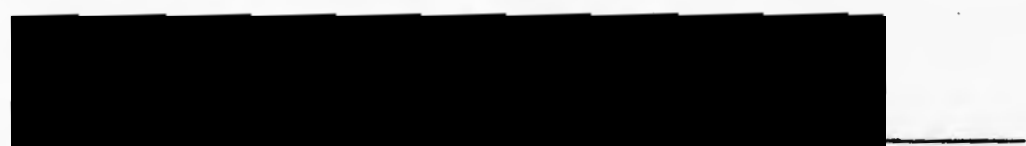

C. Donald Nelson

APPROVED:

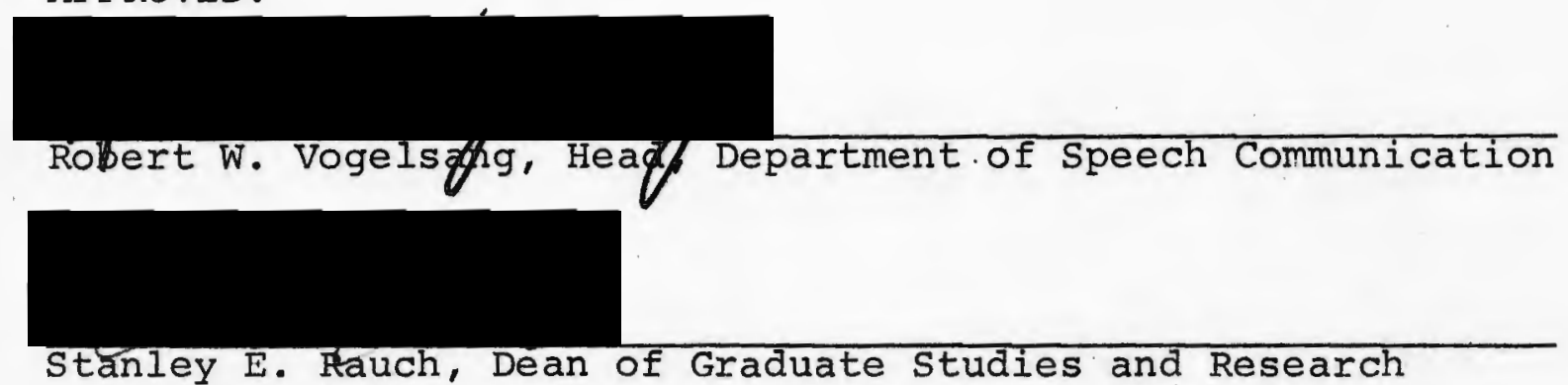




\section{ACKNOWLEDGMENTS}

This study was the product of the combined efforts and encouragement of many individuals. I am particularly appreciative of the guidance and patience given throughout the study by Dr. R. I. Casteel, my advisor and committee chairman. Thanks go also to the members of the committee whose constructive criticism was very helpful in the total design of the study. My special thanks go to Dr. C. D. Nelson, for his advice in the test construction, and to Joan McMahon, for her assistance in analyzing the subject responses. I also appreciate the guidance of $\mathrm{Dr}$. T. G. Grove concerning the organization and statistical analysis of the data.

I wish to express sincere thanks to H. F. Bates, Director of Special Services in the Oregon City Schools, who arranged for the study to be conducted in part in the oregon City Schools. This study would not have been possible without the cooperation of the principals, teachers, parents, and students of King and Gaffney Lane Elementary Schools. I also thank the staff, parents, and children at Friendly House Community Center and at Fruit and Flower Day Nursery for their substantial participation. Thanks go also to Marti Marvin, speech pathologist, for her encouragement and assistance, and to Karen Stover, for her assistance in pre- 
paring and typing the thesis.

Most important of all has been the continued encouragement and moral support rendered by my closest friends and family who have been generously patient and understanding throughout my educational program. I express my deepest appreciation to my mother and father and to my husband, Richard, who have supported me financially and inspirationally. I dedicate this work to both my parents, who have been a primary motivating force, and to Richard, without whose affection and confidence I could not have persevered. 
TABLE OF CONTENTS

PAGE

ACKNOWLEDGMENTS . . . . . . . . . . . . . .

LIST OF TABLES . . . . . . . . . . . . . . . vii

LIST OF FIGURES . . . . . . . . . . . . . . . $\mathrm{x}$

CHAPTER

I INTRODUCTION . . . . . . . . . . I 1

Statement of Purpose

II REVIEW OF THE IITERATURE . . . . . . . . . 4

Development in Meaning 4

Sequence of Task Difficulty . . . . . 11

Bases for Judging "Same" and "Different" 18

summary . . . . . . . . . 27

III METHODS . . . . . . . . . . 29

Subjects . . . . . . . . . . . 29

Chronological Age

Speech and Language

Vocabulary Recognition

Socioeconomic status

Sex

Procedures . . . . . . . . . .

Test Construction and Administration

Classification of Responses

Analysis of the Data

IV RESULTS . . . . . . . . . . . .

Appropriateness of Responses .... . 
Mean Number of Appropriate Responses

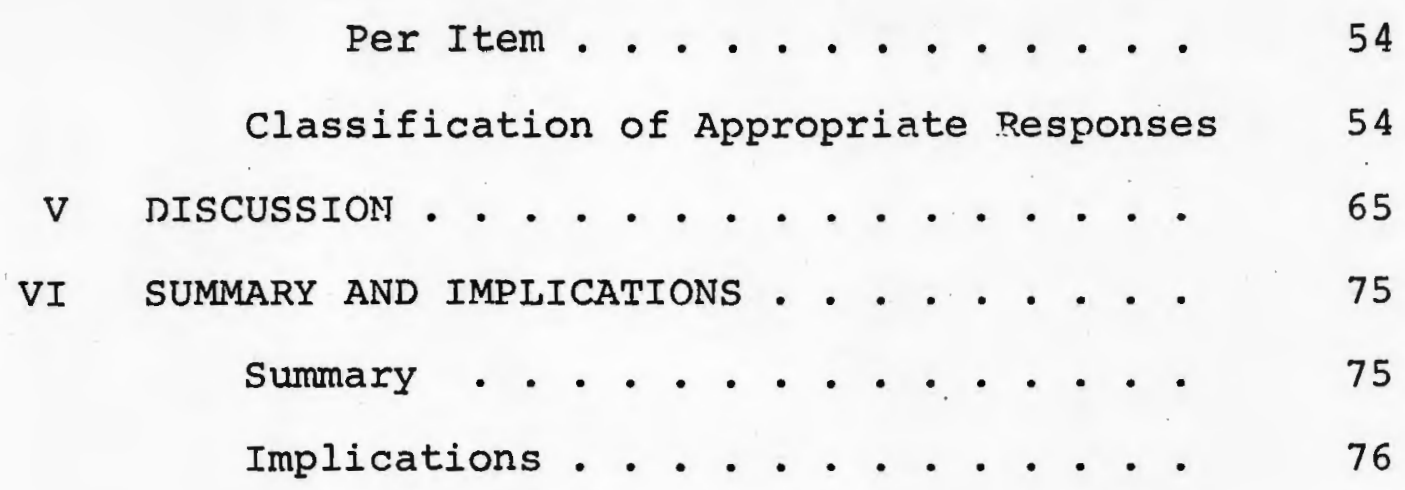

Clinical Implications

Research Implications

REFERENCES

Appendix A: List of Items and Description of Materials ..........

Appendix B: Guidelines for Judging Appropriateness . . . . . . . .

Appendix C: Examples of Response Classification ........... 


\section{IIST OF TABLES}

TABLE

PAGE

I Means and Standard Deviations for a Measure of Socioeconomic Status for Five Age Groups . . . . . . . . . . .

II Group Means, Corresponding Percentages, and Number of Subjects Above and Below the Means on the Total Test. . . . . . .

III Analyses of Variance and Trend on the Effect of Age on Performance on the Entire Test Across Seven Age Groups. .

IV Group Means, Corresponding Percentages, and Number of Subjects Above and Below the Means on Difference and Similarity Items

$V$ Analyses of Variance and Trend on the Effect of Age on Performance on the Difference Items Across Seven Age Groups

VI Analyses of Variance and Trend on the Effect of Age on Performance on the Similarity Items Across Seven Age Groups. . . . .

VII Group Means, Corresponding Percentages, and Number of Subjects Above and Below the Means on Object, Picture, and word Items 
VIII Analyses of Variance and Trend on the Effect of Age on Performance on the object Items Across Seven Age Groups . . . . . . .

IX Analyses of Variance and Trend on the Effect of Age on Performance on the Picture Items Across Seven Age Groups . . . . .

$x$ Analyses of Variance and Trend on the Effect of Age on Performance on the Word Items Across Seven Age Groups . . . . . . .

XI Percentage of Subjects in Each Age Group who Answered at least 75 Per Cent of Total Items Appropriately . . . . . . . . 50 XII Percentage of Subjects in Each Age Group Who Answered at least 75 Per Cent of Difference and Similarity Items Appropriately .

XIII Percentage of Subjects in Each Age Group who Answered at least 75 Per Cent of Object, Picture, and Word Items Appropriately . .

XIV Mean Number of Appropriate Responses Per Item By Age Group. . . . . . . . . . . . .

$\mathrm{XV}$ Means, Standard Deviations, and $T$-Values for Mean Number of Appropriate Responses Per Item at Successive Age Groups and Between Six-Years, Six-Months and Nine-Years, Six-Months $(I V-V I) . . . . . . . .$. 
XVI Percentage of Responses in Three Response Types By Age Group . . . . . . . .

XVII Percentage of Type I-Perceptible Responses on Difference and Similarity Items . . . 59 XVIII Percentage of Type II-Functional Responses on Difference and Similarity Items . .

XIX Percentage of Type III-Nominal Responses on Difference and Similarity Items. . . .

XX Percentage of Type I-Perceptible Responses on Object, Picture, and Word Items . .

XXI Percentage of Type II-Functional Responses on Object, Picture, and word Items . .

XXII Percentage of Type III-Nominal Responses on Object, Picture, and Word Items. . .

XXIII Percentage of Children in Each Age Group who Used the Same Response Type on at least 80 Per Cent of the Items ... . . . . 


\section{LIST OF FIGURES}

FIGURE

PAGE

1 Mean Number of Total Test Items Answered Appropriately by Age Group . . . . . .

2 Comparison of Mean Number of Items Answered

Appropriately on Difference Items and

Similarity Items by Age Group. . . . .

3 Comparison of Mean Number of Items Answered

Appropriately on object, Picture, and

Word Items by Age Group. . . . . . .

4 Percentage of Subjects in Each Age Group

Who Answered at least 75 Per Cent (14

Items) of Total Items Appropriately. . .

5 Percentage of Subjects in Fach Age Group

Who Answered at least 75 Per Cent $(7$

Items) of Difference and of similarity

Items Appropriately. . . . . . . . . .

6 Percentage of Subjects in Each Age Group

Who Answered at least 75 per cent (5

Items) of Object, Picture, and Word

Items Appropriately. . . . . . . . .

7 Relative Contribution of Three Response Types

to Total Appropriate Responses on the

Test as a Whole Across Seven Age Groups 
8 Comparison of the Percentage of Responses Among Difference and Similarity Items That Were Type I-Perceptible Responses

9 Comparison of the Percentage of Responses Among Difference and Similarity Items That Were Type II-Functional Responses

10 Comparison of the Percentage of Responses Among Difference and Similarity Items That Were Type III-Nominal Responses

11 Comparison of the Percentage of Responses Among Object, Picture and word Items That Were Type I-Perceptible Responses

12 Comparison of the Percentage of Responses Among object, Picture, and Word Items That Were Type II-Functional Responses

13 Comparison of the Percentage of Responses Among object, Picture, and word Items That Were Type III-Nominal Responses 


\section{CHAPTER I}

\section{INTRODUCTION}

The acquisition of "same" and "different" is a complex and gradual process, involving development in the child's understanding of these relational terms (Klatzky, Clark, and Macken, 1973; Webb, Oliveri, and O'Keefe, 1973; Donaldson and Wales, 1970); involving progression in the type of tasks to which the child can apply his understanding of "same" and "different" (Glucksberg, 1975; Klausmeier, Ghatala, and Frayer, 1974; Wechsler, 1967; Vygotsky, 1962; Terman and Merrill, 1960); and also involving development in the basic concepts upon which the child bases his judgments of similarity and difference (Miller and Starzec, 1974; Wechsler, 1971, 1967, 1955; Greenfield, Reich, and Olver, 1966; Olver and Hornsby, 1966; Inhelder and Piaget, 1964). Wechsler (1967) observed that children as young as four years could spontaneously identify and select things that go together, but not until the age of seven years could children "conceptualize this relationship verbally." Vygotsky (1962) observed that at the non-verbal level, children demonstrated an understanding of similarity earlier than they demonstrated an understanding of difference. However, when older children learned verbally to explain relationships between 
objects, they could explain differences before they could explain similarities (Vygotsky, 1962; Wechsler, 1967; Terman and Merri11, 1960). Olver and Hornsby (1966) found a progression with age from perceptible properties to common functions as the basis for similarity judgments. The tables in the manual of the Wechsler Intelligence Scale for Children (Wechsler, 1967) revealed a steady increase between the ages of six years and seventeen years in the quality of verbal explanations of similarity, indicating a progression from specific attributes and functions to general classifications as bases for similarity judgments.

While various researchers investigating the development of the concepts "same" and "different" have made inferences on the basis of non-verbal sorting, matching, and discrimination tasks (Glucksberg, 1975; Miller and Starzec, 1974; Beving and Eblen, 1973; webb et al., 1973; Politzer, 1971; Donaldson and Wales, 1970; Hall, Caldwell, and simpson, 1967), few researchers have focused on verbal explanations of similarity and difference. Those who have looked at verbal explanations have been primarily concerned with either similarity or difference but not both, and for the most part, they have limited the procedures to one type of task: either comparison of objects (Webb et al., 1973; Greenfield et al., 1966); comparison of pictures (Blank, 1972; Olver and Hornsby, 1966); or comparison without any visual referents (Wechsler, 1971, 1967, 1955; Olver and 
Hornsby, 1966; Terman and Merril1, 1960). In studies employing objects or pictures, a sorting or matching task usually preceded the verbal explanation. None of the above studies involved verbal performance of one group of children on a variety of separate tasks or qualitatively analyzed verbal explanations of difference on any task.

\section{Statement of Purpose}

The purpose of this study was to determine the influence of chronological age and stimuli on the explanations of "same" and "different" by young children. Specific questions were:

1. At what age do children verbally explain similarities and differences?

2. What effect does a change in stimuli have on the appropriateness of the responses?

3. Do the number and type of properties on which children base their explanations of similarity or difference vary with age?

4. Does the content of the explanations vary as the stimuli vary from (a) actual objects which the children may view and manipulate, to (b) pictures of objects, to (c) verbal reference to the objects without any visual representation? 


\section{CHAPTER II}

\section{REVIEW OF THE LITERATURE}

For the purpose of this study, a review of the literature will focus on three major areas concerning the development of the concepts "same" and "different": (I) development in the meaning of "same" and "different," (2) sequence of difficulty of tasks involving the judgment of "same" and "different," and (3) bases upon which judgments of "same". and "different" are made.

\section{DEVELOPMENT IN MEANING}

Several studies on the acquisition of relational concepts have shown that children do not learn polar adjectives symmetrically. The acquisition of one member of the pair generally precedes the other (Wood, 1976; Klatzky et al., 1973; Donaldson and Wales, 1970). Clark (1970) suggested a three-stage development in the acquisition of polar adjectives. In antonym pairs (eg., long, short), the member which indicates the presence of an attribute (eg., long indicates length) is designated as the positive pole. During the first stage of development, both words are used synonymously in the nominative sense (eg., The snake is a foot long/short). In the second stage, the child begins to 
differentiate the polar adjectives, using the positive pole correctly in the contrastive sense (eg., The rope is long). The appropriate contrastive use of the negative pole (eg., The snake is short) is the third stage, completing the developmental process. Following this developmental theory, the first stage helps to explain the synonymous use of polar adjectives by young children and explains the higher frequency of accurate use of the positive pole than the negative pole. Fein and Eshleman (1974) suggested that the confusion young children demonstrate in dealing with "same" and "different" could be explained by the asymmetrical development of these two words as polar adjectives.

Other researchers (Glucksberg, 1975; Webb et al.,

1973; Clark, 1970; Donaldson and Wales, 1970) questioned the applicability of this developmental model to the acquisition of the concepts "same" and "different." While "same" and "different" suggest an antonym relationship, they are not straightforwardly opposite (Donaldson and Wales, 1970), even for adults (Glucksberg, 1975; Kaplan, cited in webb et al., 1973).

In a study involving eighteen adults on a selection task with common objects (Kaplan, cited in webb et al., 1973), ten subjects consistently chose a maximally different object when requested to select an object "different" from a target object. One subject chose maximally similar objects, justifying his choice by saying that it was a "different" 
(in other words, "another") red square, or whatever the case had been. The remaining seven subjects were not consistent but tended to choose objects with a dimension of similarity with the target. Commenting on these results, Webb et al. (1973) remarked that any choice to the request "different" can be justified.

Glucksberg (1975) found that adults frequently interpret "different" to mean "another," and will select an object of the same type (maximally similar) or function (similar within a class) in response to a request for "a different one." After repeated trials of the same task, a majority of the subjects expressed confusion as to the intent of the experimenter, demonstrating the ambiguity of the word "different" in adult language.

Donaldson and Wales (1970) described several levels in meaning for sameness:

1. When two or more objects are alike with respect to all observable attributes.

2. When two or more objects are alike with respect to at least one observable attribute, but different with respect to at least one other attribute.

3. When two or more objects are alike in some respect that is not directly observable.

a. This may involve the combined consideration of attributes, each of which, taken separately, is observably different.

b. This may depend on previous perception of an attribute which is not actually observable at the time the judgement is made.

In normal adult usage, "same" can refer ambiguously to any 
one of these relationships. Depending upon the attributes under consideration, nearly any two objects can be either "same" or "different.".

The ambiguity in the meaning of "same" and "different" is reflected by the development in meaning of these words in the language of young children. By analyzing the response choices of preschoolers on a selection task involving judgments of "same" and "different" with common objects, and by incorporating the results of an earlier study by Donaldson and Wales (1970), Webb et al. (1973) constructed a fourstage model in the development of meaning of "different":
Stage I--Children three-years, two-months and younger reversed the meaning of "dif- ferent" for "same."

Stage II--Children three-years, three-months to three-years, six-months interpreted "different" to mean "another" of the same type.

Stage III--Children three-years, six-months or three-years, seven-months and older believed "different" required a dimension of similarity.

Stage IV--older children [age not specified] were indistinguishable from adults.

In Stages I and II, children selected objects that were maximally similar to the target object. In both stages, "same" and "different" referred to object identity. While in Stage I, they were synonyms, in Stage II "same" and "different" were differentiated, and "different" meant a denial of identity of the target object. In Stages III and IV, children correctly chose objects that differed on 
at least one dimension from the target. Here "same" and "different" referred to similarity relationships.

In light of subsequent studies involving adults (Kaplan, cited in Webb et al., 1973; Glucksberg, 1975), the validity of stage IV is questionable. While the behavior characteristic of stage IV is not clearly specified, it is implied that adults and older children select objects of maximum difference. Yet even adults are inconsistent as a group in their selection behavior, a sizeable portion continuing to select objects with a dimension of similarity, characteristic of Stage III. A more important distinction between Stage III children and older children and adults might be the flexibility of the latter group in appropriately assessing the situation at hand to determine what criteria to apply in making "same/different" judgments.

An important part of the situation is the intent of the speaker and the language he uses to direct the selection task. Webb et al. (1973) investigated the influence of different terminology and found that on a non-verbal selection task, children between the ages of three-years, one-month to five-years, seven-months did not respond differentially to the terms "the same as" and "alike" or to the terms "different" and "not alike." Glucksberg (1975) also investigated the influence of language usage. He maintained that even young children, like adults, respond to utterances by inferring the intent of a speaker's message. In response to 
the utterance, "Give me one that is different from this," young children and a significant number of adults interpreted the request to be for "another one of similar type" (Glucksberg, 1975; Webb et al., 1973; Donaldson and Wales, 1970). Glucksberg (1975) pointed out that a failure to differentiate "same" and "different" imbedded in an utterance may not demonstrate a failure to differentiate between "same" and "different." Challenging the conclusions of previous researchers that three-year-olds do not differentiate "same" and "different," Glucksberg observed the selection behavior of six preschoolers, ranging in age from two-years, eight-months to three-years, three-months. A replication of the Donaldson and Wales (1970) procedure obtained the same results. However, on a task in which the attribute relevant to the "same/different" judgment was specified and unambiguous (i.e., Give me one that's the same/different color as this one), these young preschoolers correctly responded nearly 100 per cent, demonstrating at least a fundamental understanding of "same" and "different." While the subject population was small, these consistent results demonstrated the significant influence of language usage and task on the interpretation on meaning of "same" and "different."

A major source of the ambiguity inherent in "same" and "different" is the fact that there is no physical dimension which is their obvious referent (Webb et al., 1973). "Same" 
and "different" do not refer to any particular physical dimension but to an infinite number of possible similarity relations (Webb, Oliveri, and O'Keefe, 1974). The criteria for sameness and difference varies with the nature of the stimuli being compared and depends upon the task and the intent of the speaker requesting or making the judgments. Therefore, in order to appropriately judge sameness or difference, a person must know what constitutes sameness and difference specific to a situation. It is possible that children error in their judgments of "same" and "different" not because of a lack of basic understanding of the words, but because of a failure to determine the relevant dimensions for comparison in given situations.

In summary, the inherent ambiguity of the words "same" and "different" complicates the acquisition of these concepts in the language of children. These words are ambiguous in that they may refer to either identity or similarity relationships. Also the criteria for sameness and difference changes with the situation and the stimuli being compared. For any two objects, it is possible to justify a conclusion that they are the same in some way or different in some way. However, within a cultural group, there is a general consensus over what a person implies when he asks a question about similarity or difference (Webb et al., 1973). With increasing age, involving cognitive and social development, children are able to perform an increasing variety of 
tasks requiring "same/different" judgments. Wechsler (1967) observed that children as young as four years can identify and select things that go together, but not until age six or seven can they conceptualize this relationship verbally. A review of current studies and intelligence measures suggests a sequence in "same/different" tasks that the maturing child can perform.

\section{SEQUENCE OF TASK DIFFICULTY}

Glucksberg (1975) demonstrated that children as young as two-years, eight-months to three-years, three-months can differentiate "same" and "different" by selecting an object that is either the same as or different from a target object, when the relevant attribute is specified and unambiguous, and when other attributes are constant. On this task, all objects were beads differing only in color. A "same" choice could only be two identical beads. Beads of different color represented a "different" choice.

on the Stanford-Binet Intelligence Scale (Termin and Merrill, 1960), the first task involving a "same" or "different" judgment appears at the four-years, six-months level $($ IV-6). This non-verbal task involving pictures requires the child to point to the one that is "not the same" as the others. On a similar task, appearing in the Boehm Test of Basic Concepts (Boehm, 1971), the child marks the figure that is "different" from the others. Here the figures vary 
on only one dimension. The percentage of children passing this item are seventy-three to eighty-six per cent of kindergarten children, ninety-five to one hundred per cent of first graders, and ninety-nine to one hundred per cent of second graders. These figures are based on a middle socioeconomic status sample taken at the beginning and middle of the academic year.

A second "same/different" task on the stanford-Binet Intelligence Test (Termin and Merrill, 1960), appears at the five-year level (V). It involves pairs of pictures and requires a verbal "yes"/"no" response to the question, "Are they alike? Are they the same?"

In the tasks above, the criteria for sameness is absolute identity. In other words, only stimuli which are identical in all respects are considered to be "same," and all objects differing on at least one dimension are considered to be "different." While the tasks are similar in many respects, the points on which they differ may be significant enough to account for the difference in performance age. In the Glucksberg (1975) task, the stimuli were three objects, and the attribute relevant to the "same/different" judgment, color, was specified. In the other tasks, the stimuli consist of two-dimensional pictures, and the relevant attributes, such as size and form, are not specified. While in the Glucksberg task, the child was really judging sameness and difference of one dimension, color, in the other 
tasks, the child judged sameness and difference of the whole object. Furthermore, color has more salience for the young child than other attributes, such as size or form (Greenfield et al., 1966). Also the young child has more experience with three-dimensional objects, such as beads, than with two-dimensional pictures (Money, 1966). While a real difference in task difficulty attributable to some or all of these variables may exist, the small population in the Glucksberg (1975) study and the lack of a standard criterion level of performance among the tasks prevent a meaningful comparison of the data.

Just as task and stimuli appear to be important determinants in the age at which children can perform non-verbal selection tasks, task and stimuli may be equally important in determining the age at which children can explain verbally similarities and differences. Apparently the least difficult of the verbal tasks is verbal justification of preceding non-verbal selection responses. With two exceptions, children as young as three-years, three-months appropriately referred to differences in their justifications even though one-third of these children consistently selected maximally similar objects rather than different objects on all trials (Webb et al., 1973). The youngest children able to explain verbally differences between two objects were the children three-years, seven-months and older of the Webb et al. study who were consistently correct in the selection of 
"different" objects.

In two similar studies (Greenfield et al., 1966; Olver and Hornsby, 1966), older children were selected to perform verbal justification tasks which involved the grouping of similar stimuli. In the Greenfield et al. (1966) study in which common objects were employed as stimuli, the youngest children ranged in age from six to seven years. Olver and Hornsby (1966) employed colored drawings of common objects and included thirty first graders with a mean age of sixyears, three-months as the youngest subjects. Because the primary interest of both studies was to analyze the content of the verbal justifications and not simply to determine the youngest age at which children could perform the task, these ages represent ages at which children were consistent in appropriately explaining similarities. Because the studies involved two distinct subject samples, and because the ages are not young enough to indicate zero performance level, it is impossible to compare the effect of the different stimulus types (objects and pictures) on the verbal performance.

While the form of the stimuli has been discussed as an important determinant in performance, nothing has been said about the effect of the concepts represented by the stimuli. For instance, Blank (1972) has pointed out that when two objects share a common referrent children tend to describe similarities between the objects, regardless of the 
degree to which they may appear dissimilar. Also children tend to describe differences between objects which do not share common referrents, no matter how similar.

No doubt the highest level of task difficulty is the verbal explanation of similarities and differences in the absence of visual representations of the things being compared. In the verbal tasks of the Stanford-Binet Intelligence Scale (Terman and Merrill, 1960) and the Manual for Evaluation of Speech, Language, and Hearing Development in Children (Crippled Children's Division, 1958), neither objects or pictures are presented to the child. He can neither select nor manipulate the things which he is requested to compare. Consequently the performance ages assigned to both the "difference" and "similarity" tasks in these scales are much older than the ages represented in the studies employing selection of objects or pictures. Both the Stanford-Binet Intelligence Scale (Terman and Merrill, 1960) and the Manual for Evaluation of Speech, Language, and Hearing Development in Children (Crippled Chilaren's Division, 1958) assign an age of six-years to the explanation of difference task; whereas, Webb et al. (1973) have demonstrated that children as young as threeyears, seven-months can consistently explain differences between objects they have selected as different. The Stanford-Binet Intelligence Scale (Terman and Merrill, 1960) and the Manual for Evaluation of Speech, Language, and 
Hearing Development in Children (Crippled Children's Division, 1958) assign the ages of seven years and seven-years, six-months, respectively, to the explanation of similarity task, even though children by the age of six-years, threemonths to six-years, seven-months can consistently explain similarities between pictures or objects they have grouped as similar (Greenfield et al., 1966; Olver and Hornsby, 1966). From the limited data, it is not clear which component of the task is the significant factor accountable for the difference in performance ages: the presence of visual representations or the opportunity to select the stimuli to be compared. No doubt both factors influence the verbal performance to some extent.

Wechsler (1967) offers an explanation as to why children may be able to explain verbally differences before they can verbally explain similarities. He maintains that it is easier for a young child to state attributes separately for each object, than to abstract a common attribute of two dissimilar objects. Thus it is more probable that the young child will state a difference rather than a similarity, the similarity requiring a greater degree of abstraction. On all three of the Wechslex Scales of Intelligence (1971, 1967, 1955), verbal explanation of similarities is included as a subtest. Because of the scoring procedures, in which the content of the explanations is analyzed and scored on a zero-to-two point scale, it is impossible to state at what 
age a given percentage of the children are able to perform the task. There is a consistent development with age in the quality of explanations, indicating a movement from reference to specific attributes or functions to reference to general classification. On the Wechsler Preschool and Primary Scale of Intelligence (Wechsler, 1967), sentence completion analogies are also included in the Similarities subtest, further confounding possible interpretations of the normative data. By the age of seven years, on the Wechsler Intelligence Scale for Children (Wechsler, 1971), the median performance on the similarities subtest is a score of eight points of a possible thirty points, indicating the difficulty of this verbal task in the absence of visual representations of the things being compared. Not until the age of eleven years, does the median score represent fifty per cent of the total possible points.

In summary, the maturing child demonstrates a development in understanding of the concepts "same" and "different" by his performance on increasingly more difficult tasks requiring "same/different" judgments. By the age of five years, most children should have little to no difficulty in making "same/different" judgments with objects or pictures, although they may tend to accept only identity with respect to all attributes as the criterion for sameness. Children younger than about three-years, six-months cannot be expected to appropriately select a "different" object unless the 
relevant attributes for a "different" judgment are specified and unambiguous, in which case children as young as two years, eight-months may respond appropriately. On nonverbal selection tasks, children may learn "same" before "different," especially when absolute identity is the criterion for sameness. On verbal tasks, children learn to explain differences between objects before they can explain similarities. Depending upon the nature of the task and the stimuli involved, children can consistently explain differences as young as three-years, seven-months. By six years of age or younger, children can explain similarities. The failures to explain similarities by older children and adults is probably due to increasing levels of abstraction in the stimuli to be compared.

\section{BASES FOR JUDGING "SAME" AND "DIFFERENT"}

Because "same" and "different" always refer to things and their attributes, development of the concepts "same" and "different" are in part dependent upon development of a variety of other concepts, including both the things being compared and the attributes which constitute the relationship of similarity or difference. Several researchers have used tasks involving "same/different" judgments or explanations of similarities and differences as a means of investigating cognitive and perceptual development (Klausmeier et al., 1974; Miller and Starzec, 1974; Webb et al., 1973; 
Wechsler, 1971, 1967, 1955; Vygotsky, 1962; Greenfield et al., 1966; Olver and Hornsby, 1966; Inhelder and Piaget, 1964; Terman and Merrill, 1960). They have found a progression in the bases upon which children judge similarity and difference that reflects general cognitive and perceptual development.

Miller and Starzec (1974) found age-related differences in the number and type of attributes upon which "same/ different" judgments were based. The task involved the free-classification of stimuli which consisted of figures drawn on cards, each varying from another on zero-to-four attributes: form, orientation, size, and brightness. Preschoolers and first graders tended to classify on the basis of one attribute, while third graders predominantly demonstrated the use of multiple-attribute classification. All who classified on the basis of one attribute used form as the discriminating attribute, while those who demonstrated two-attribute patterns used form and orientation as the bases for classification. Size was used only by children who classified on the basis of three-attributes, and brightness (represented by two shades of gray) was ignored as a relevant attribute. A verbal post-test revealed that the children were able to detect more attributes than they used in classification. It was concluded that the age-related differences in number and type of attributes used in classification are related to an age-related increase in degree of 
salience of a variety of attributes, as a result of increased opportunities for perceptual learning.

While Miller and Starzec (1974) restricted the relevant attributes of the stimuli to form, orientation, size, and brightness, other researchers have reported that young children demonstrate a preference for color as the basis for comparison. In the study of webb et al. (1973), a substantial number of three-year-olds always referred to color differences in justification of their selections of different objects. Using water-color drawings of common objects as stimuli, Olver and Hornsby (1966) found that children who relied on perceptible attributes predominantly used color as the basis of classification.

of course, "same/different" judgments can be based on more than just color, size, and form. Other areas of possible comparison include (Teaching Resources Corporation, 1974):

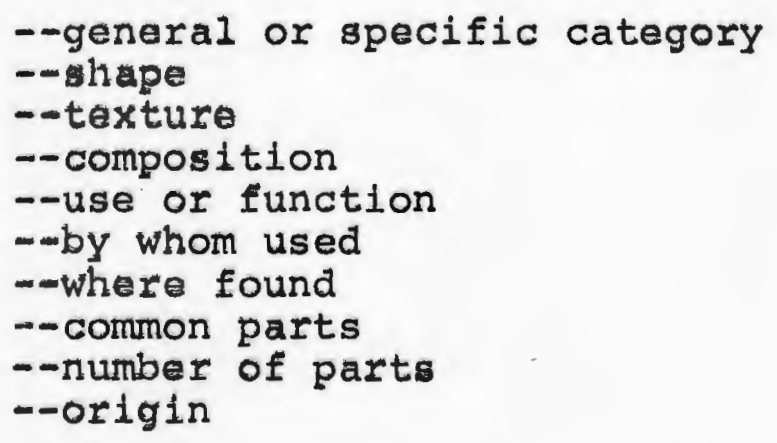

It would appear that the list is potentially infinite, depending upon the stimuli being compared.

On the Stanford-Binet Intelligence Scale (Terman and Merri11, 1960) stubtests involving verbal explanations of 
similarities and differences, any real likeness or difference, whether fundamental or superficial, is given credit, and all acceptable responses are given equal credit. However, on the Wechsler Scales of Intelligence (Wechsler, 1971, 1967, 1955) subtest involving verbal explanation of similarities, responses are scored on a three-point scale. The maximum credit, two points, is given to any general classification which is primarily pertinent for both members of the pair. The credit of one point is given to any reference to specific properties or functions which are common to both and constitute a relevant similarity. No credit is given to reference to specific properties of each member of the pair, to generalizations which are incorrect or not pertinent, to reference to differences between the members of the pair, or to clearly wrong responses. The tables of scale score equivalents for raw scores on the Similarities subtest reveal an increase with age in the total scores. Because of the differential scoring procedures, it cannot be inferred whether the increase in total score represents an increase in the number of two-point or one-point responses. Assumedly, a score greater than fifteen (fifty per cent of the maximum credit) indicates that the child must be making general classifications on at least some of the items.

Movement from specific attributes and function to general classifications as bases for similarity judgments parallels the latter stages in cognitive development pro- 
posed by Piaget, as discussed by wood (1976). According to Piaget, children between the ages of two years and seven years demonstrate "preoperational intuitive thinking." At this stage, their judgments about relationships are limited by their attention to only one property at a time. On the Similarities subtest of the Wechsler Intelligence Scale for Children (Wechsler, 1967), the average six-year-old receives twenty per cent of the maximum score. Between the ages of seven years and eleven years, following the Piagetian model, children acquire an understanding of complex relationships and classify objects according to a wide range of criteria. At this stage of "concrete operational thinking," children have trouble in dealing with abstractions and events not visible to them. During this same period, the average child improves in performance on the similarities subtest (Wechsler, 1967) from about twenty-five per cent to forty-five per cent of the maximum score. Eleven years marks the beginning of "formal propositional thinking" (Wood, 1976). Accordingly, from eleven years to seventeen years, the score of the average child on the Similarities subtest (Wechsler, 1967) increases from forty-five per cent to seventy per cent of the maximum score, demonstrating an increase in general classifications and abstractions.

Klausmeier (1975) proposed a model of concept development by which concepts are attained at four successively higher levels in an invariant sequence: concrete level, 
identity level, classificatory level, and formal level. Recognizing a resemblance to the piagetian model in particular, Klausmeier (1975) drew two distinctions between his developmental model and those presented by previous researchers. The first is that the level of concept attainment varies among children of the same age. Secondly, he stated that various concepts are attained by the same children at different rates. In other words, while a child may have attained the formal level for one concept, he may still be at the concrete level with another concept. At the classificatory level, a child can demonstrate non-verbally that he recognizes equivalent attributes in different objects; however, not until the formal level can the child explain the basis for his judgment of equivalence (Klausmeier et al., 1974).

On the basis of the above discussion, it is apparent that the quality of a child's verbal explanations of similarities and differences between concepts will vary to the extent that different concepts are attained at different times by the given child. Therefore, while it may be possible to describe a general development in the verbal explanation of relationships of similarity and difference in any specific situation, special consideration must be given to the specific concepts being compared.

As part of an investigation of cognitive development, Olver and Hornsby (1966) studied the content of verbal 
explanations of similarity and difference of sixty children ranging in age from six-years, three-months to eighteenyears, seven-months. The subjects named the items to be compared, in groups of two to five items, without reference to either pictorial representations or actual objects. The children demonstrated five modes of response that were categorized as:

1. Perceptible - phenomenal qualities such as color, size, shape, or position in time or space.

2. Functional - function of the item, considering either what they do or what can be done to them.

3. Affective - an emotion they arouse or an evaluation of them.

4. Nominal - a name that exists ready-made in the language.

5. Fiat - merely stating that they are alike without explanation.

The results of this study indicated that six-year-olds rely on perceptible attributes more than do older children. From six years on, there was a steady increase in functionally based equivalence. Whereas functional attributes constituted forty-nine per cent of all responses at six years, by nineteen years functional attributes constituted seventythree per cent of the responses.

In another aspect of the same study, Olver and Hornsby (1966) presented ninety children, ranging in age from six to eleven years, with a two-part grouping task. First each child was asked to choose from an assortment of forty-two water-color arawings a group of pictures that were alike in 
some way. Following the selection the child was asked to tell how the pictures he had selected were alike. The complete task was repeated ten times for each child. On the basis of verbal explanations the results indicated an increase with age in the use of functional attributes as the basis of grouping "like" objects. The most dramatic increase was seen between six years and nine years, after which the increase continued but was considerably slower. On the non-verbal task, the grouping behavior appeared to be determined with no reference to function; however, when the children then described the groups functional characteristics were used to explain the similarities. Accompanying the increase in use of functional attributes, there was an increase in the use of nominal classifications.

Greenfield et al. (1966) studied the selection and justification behaviors of children on a task similar to the Olver and Hornsby (1966) task and obtained similar results. In this study actual objects served as the stimuli and verbal responses were classified in three major categories: perceptible, function, and nominal. They observed that nominal classification is implicitly functional in that common names generally reflect common usage. In the functional category, Greenfield et al. (1966) distinguished between personal (for example, "We eat them") and impersonal (for example, "They can be eaten") references. They found that at all ages, white American children made more personal 
references than impersonal references, although there was a slight decrease in personal references with age. Interestingly, Eskimo children made fewer personal references than impersonal references, with no appreciable difference with age. Greenfield et al. (1966) hypothesized that the use of personalized functional references exhibited egocentrism, and that Eskimo children did not exhibit egocentrism to the extent that white American children did, as a reflection of Eskimo culture which holds ideals of cooperation and subordination of the individual to the group.

Conflicting results were found by Maccoby and Modiano (1966) who studied the effect of culture on judgments of similarity and difference. They compared the performance of samples of Mexican village children and Mexican city children on a selection-justification task. By age thirteen, there was a dramatic difference in the use of impersonalized functional and nominal references between the two groups. The researchers explained that,

- . while the modern industrialized world demands abstractions, the village life of the peasant requires attention to the concrete physical environment with which he is closely involved (Maccoby and Modiano, 1966).

Consequently, the city children made many more references to impersonalized function and nominal classifications than did the village children.

The composite results of all of the above studies have demonstrated a progression with age from specific perceptible 
attributes, to functional properties, to nominal classifications, as bases for judgments of similarity and difference. Within functional properties, there was movement from personal to impersonal references. Within perceptible attributes, there was an increase in the number and type of attributes determined by age-related differences in the degree of salience of different attributes. Task and stimuli were revealed to influence significantly the bases upon which comparative judgments were made. Culture was also demonstrated to be a significant determinant in judgments of similarity and difference.

\section{SUMMARY}

A review of the literature suggests that there are several stages in the acquisition of the concepts "same" and "different" and that these stages depend upon a variety of factors in addition to a fundamental understanding of the two words. These factors are (I) the nature of the task (eg., pointing, grouping, Yes/No response, verbal explanation, etc.); (2) the language used to present the task and the nature of the stimuli used (eg., objects, pictures, words without visual referents, etc.); (3) the degree of abstractness of the items and of their relationship; (4) the criterion for judging similarity or difference that changes depending on the items being compared and the purpose of the comparison. Therefore, the adequacy of a child's under- 
standing of "same" and "different" is dependent upon the above factors as well as the vocabulary and basic concept development of the child.

The literature also suggests that "same" and "different" are not learned at the same rate, but that neither "same" nor "different" remain constantly ahead of the other in the acquisition process. For instance, on non-verbal tasks, young children may learn to select similar objects before they learn to select different objects. On verbal tasks, it appears that children learn to explain differences before they can explain similarities.

The literature also suggests that even after a child has acquired a basic understanding of the concepts "same" and "different," the quality of his verbal explanations of "same" and "different" continues to change. This qualitative change reflects a change in the bases upon which the child compares items. Reportedly the change in bases follows a progression from perceptible attributes, to functional properties, to nominal classifications. Furthermore, the nature of the task and the stimuli appear to influence the bases upon which comparative judgments are made.

The purpose of this study was to determine the effects of chronological age and stimuli on the verbal explanations of "same" and "different." 
CHAPTER III

METHODS

I. SUBJECTS

This study involved seventy children who were selected on the basis of chronological age, normal speech and language development, and normal vocabulary recognition. There were ten childran at each of seven age groups, beginning at threeyears, six-months, and at one year intervals up to and including nine-years, six-months. Socioeconomic status was determined for each child for descriptive purposes only. Nelther socioeconomic status nor sex was a selection criterion.

\section{Chronological Age}

The blrthdates of the children enrolled at the friendly House Community Center pre-school program and the Fruit and Flower Day Nurbery were obtained from office records. Chlldren accepted for Eurther consideration were those whose birthates fell between February 15 and June 15 , 1972, and between February 15 and June 15, 1973, so that the children were within sixty days of being four-years, six-months or three-years, six-months at the time of testing In October, 1976. Similarly, the birthdates of all children 
from kindergarten, first, second, third, and fourth grades at King and Gaffney Lane Elementary Schools, in the Oregon City School District, were obtained from school records. Children who were born between February 15 and June 15, from 1966 through 1971, were accepted for further consideration. A pool of between fifteen and twenty-three children were obtained at each of the seven age groups.

\section{Speech and Language}

Children from the pre-school and day nursery were screened by this researcher, using the Utah Test of Language Development (Mecham, Jex, and Jones, 1967). Only those who demonstrated normal speech and language development were included in the pool for random order selection. Children from King and Gaffney Lane Elementary Schools who passed the fall screening for speech and language or who demonstrated normal speech and language as determined by the school speech clinician were also included in the pool of potential subjects.

\section{Vocabulary Recognition}

Selecting children at random within each age group, the Peabody Picture Vocabulary Test, Form B (Dunn, 1959) was administered until ten children in each age group achieved scores between the twenty-fifth and seventy-fifth percentiles. The mean percentile score for the entire subject population was 55 . The range of means by age groups was 48 
to 61 .

Socioeconomic Status

As a measure of socioeconomic status, the occupation of the chief income recipient in each child's family was obtained for the children attending the Oregon City Schools. (Unfortunately administrators at the preschools would not release this information and discouraged family contacts, and measures of socioeconomic status were not obtained.) A value of 01 to 99 was assigned to each child according to the procedures in the United States Bureau of the Census Working Paper Number 15, Methodology and Scoring of Socioeconomic status (1960). The group means and standard deviations for socioeconomic status scores for these children are presented in Table I. The mean scores ranged from 44.40 to 62.80 . A series of $t$ tests for unrelated measures

TABLE I

MEANS AND STANDARD DEVIATIONS FOR A MEASURE OF SOCIOECONOMIC STATUS FOR FIVE AGE GROUPS

\begin{tabular}{|lcc|}
\hline Age Group & Mean Scores & SD \\
\hline Five-years, six-months & 53.00 & 28.43 \\
Six-years, six-months & 44.40 & 18.86 \\
Seven-years, six-months & 59.20 & 23.97 \\
Eight-years, six-months & 62.80 & 27.32 \\
Nine-years, six-months & 60.60 & 24.15 \\
\hline
\end{tabular}


revealed no significant differences at the .05 level of confidence between any pair of age groups. While there was little difference among the group means, the large standard deviations indicate much variation within age groups. However, overall the subject population five-years, six-months and older was generally representative of the middle socioeconomic class.

$\underline{\text { Sex }}$

Sex was ignored in the selection of subjects. nverall, there were thirty-one males and thirty-nine females. With the exception of nine-years, six-months, in each group of ten children there were four to six males and the remainder females. At nine-years, six-months, there were nine females and only one male.

\section{PROCEDURES}

\section{Test Construction and Administration}

Two weeks following the initial screening procedure, each child was tested individually in a quiet room provided for the purpose at each respective school or center.

The test consisted of a series of verbal tasks which involved three variations of stimuli. Proceeding in order from concrete to abstract, the stimuli included common objects, pictures of common objects, and words without visual referents. In each task situation, the child was 
asked first to explain how two items were "different" and then how two other items were "the same." Within each task situation, three trials were presented for both the explanation of difference and for the explanation of similarity. The items to be compared changed in each trial. The paired items had been carefully selected so that, for explanations of difference, the items could be contrasted with reference to any one or all of the following categories: nominal classification, function or related action, and perceptible attributes. Also for explanations of similarity, the items could be compared with reference to any one or all of the above categories. A list of the paired items in each task and a description of the stimuli have been included in Appendix A.

Before the tasks were presented, the experimenter (E) greeted the child and engaged the child in a brief, congenial conversation to establish rapport. The tasks and the experimenter's instructions to the child are presented below:

Task 1: Objects

Introducing the first task situation, E said, "I'm going to ask you some questions about some objects, and you answer the best you can."

Using pairs of common objects in three successive trials, E asked, "How are a __ and a __ different?" Following the child's explanations of difference, E said, "Now I'm going to ask you something else." 
Using pairs of common objects in three successive trials, E asked, "How are a and a the same?"

\section{Task 2: Pictures}

Introducing the second task situation, E said, "Now I'm going to ask you some questions about some pictures."

Using pairs of colored drawings of common objects in three successive trials, E asked, "How are a and $a$ different?"

Following the child's explanations of difference, E said, "Now I'm going to ask you something else."

Using pairs of drawings in three successive trials, $E$ asked, "How are a and a the same?"

Task 3: Words

Introducing the third task situation, E said, "Now I'm going to ask you a few more questions."

Using pairs of words in three successive trials, E asked, "How are a and a different?"

Following the child's explanations of difference, E said, "Now I'm going to ask you something else."

Using pairs of words in three successive trials, E asked, "How are a and a the same?"

All responses were recorded in writing by the experimenter. For an ambiguous response, the experimenter prompted, "Tell me more about that?" A pointing response was accepted if accompanied by a verbal explanation in 
response to the experimenter's prompt, "What are you pointing to? Tell me more about that." Positive social reinforcement was provided on an intermittant schedule regardless of appropriateness of response.

\section{Classification of Responses}

Four major classifications were described for the purpose of classifying all possible responses. Appropriate responses were assigned to one of three classifications, while all inappropriate responses were assigned to one classification. The guidelines used for judging appropriateness are presented in Appendix B.

The classifications were as follows:

Appropriate

1. Perceptible Attributes, including color, shape, size, weight, parts, composition, texture, sme11, flavor, etc.

2. Function or Related Action

3. Nominal Classification

Inappropriate (4), including similarity or difference when the opposite was requested, identification of each item, evaluation or description of the items that does not constitute an explanation of difference or similarity, clearly incorrect responses, no response, etc.

Examples of responses and the classifications are presented in Appendix C.

To increase reliability of the classifications used, there were two judges. As one judge, the experimenter analyzed and classified all responses. A person with several 
years experience in teaching language to children and in research and teaching in speech pathology at the college level was selected as the second judge so that extensive training in the analysis and classification procedures to be used would not be necessary. The second judge analyzed and classified a sample of 10 per cent of the responses. In judging the appropriateness of the responses, the two judges agreed on 91 per cent of the responses in the sample (115 of 126 total responses). In classifying the appropriate responses, the two judges agreed on 98 per cent of the sample responses (123 of 126 total responses).

\section{Analysis of the Data}

A series of $\underline{t}$ tests for related measures were performed to determine the significance of differences between performance on different portions of the test, within each age group. Portions of the test to be compared were Difference vs Similarity items and all combinations of object vs Picture vs Word items. To study the influence of age on test performance, analyses of variance and trend were performed. A series of $t$ tests for unrelated measures were performed to determine the significance of differences between the mean number of appropriate responses per item of successive age groups. A descriptive rather than statistical approach was used to analyze the data concerning the distribution of appropriate responses among the three response types at the different age groups and on different portions of the test. 
CHAPTER IV

RESULTS

This study investigated the influence of chronological age and stimuli on the explanations of "same" and "different" by young children. The data were organized and analyzed to determine (1) appropriateness of responses, (2) mean number of appropriate responses per item, and (3) classification of appropriate responses into three response types.

\section{APPROPRIATENESS OF RESPONSES}

Referring to Figure $I$ and Table II, performance on the test as a whole increased with age. The mean number of items answered appropriately increased from 2.1 (12 per cent) at age three-years, six-months, to 10.1 (56 per cent) at age four-years, six-months. The mean scores continued to increase at a slightly slower rate from 10.1 (56 per cent) at age four-years, six-months, to 16.7 (93 per cent) at age six-years, six-months. A slight increase was demonstrated between 16.7 (93 per cent) at age six-years, six-months, and 17.6 (98 per cent) at nine-years, six-months. According to an analysis of trend, there was a significant linear trend in the data with respect to increase in age. A significant quadratic trend dealing with the curve was also 


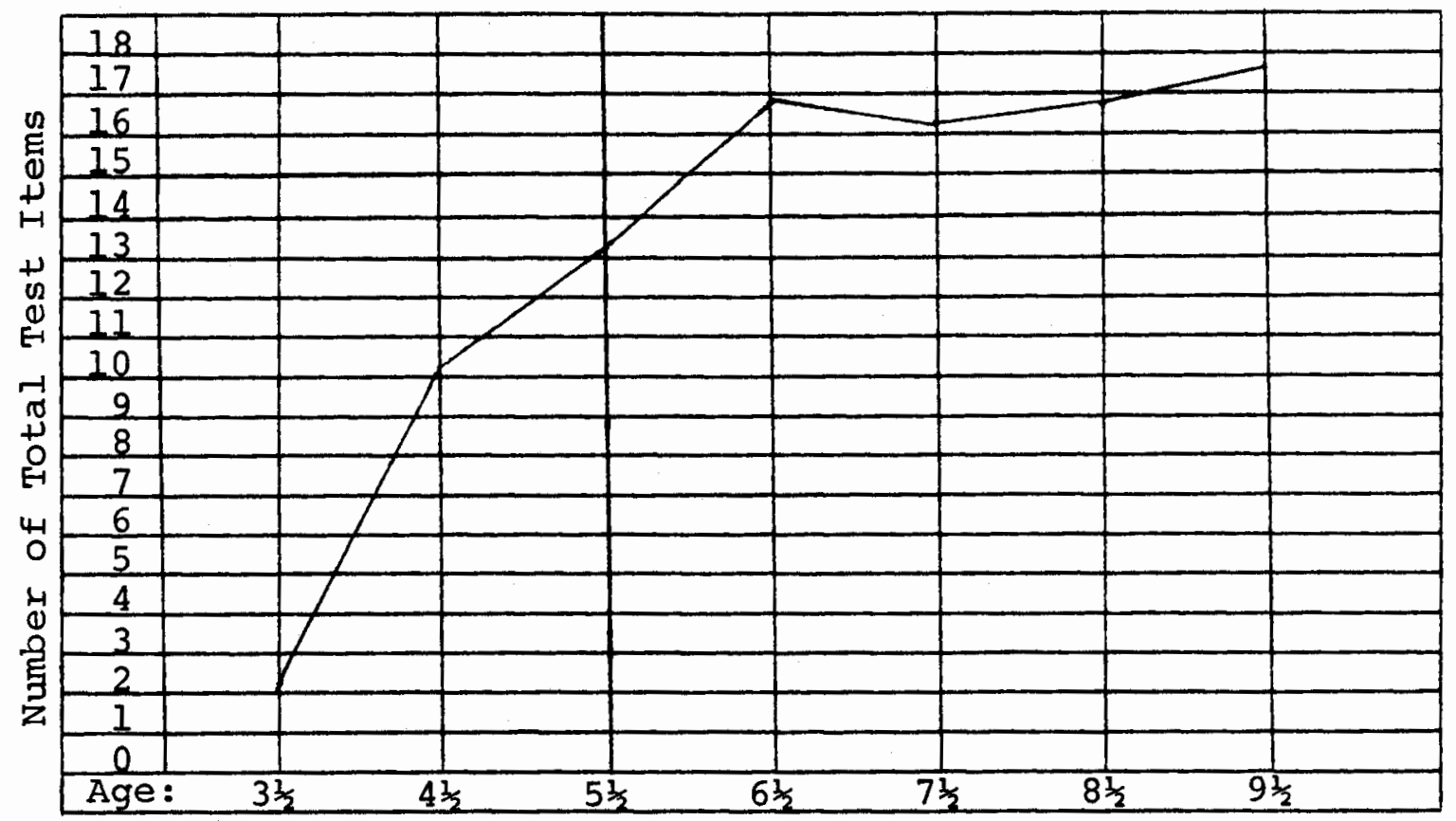

Figure 1. Mean number of total test items answered appropriately by age group.

TABLE II

GROUP MEANS, CORRESPONDING PERCENTAGES, AND NUMBER OF SUBJECTS ABOVE AND BELOW THE MEANS ON THE TOTAL TEST

\begin{tabular}{|l|c|c|c|c|c|c|c|}
\hline Age & $3 \frac{1}{2}$ & $4 \frac{1}{2}$ & $5 \frac{1}{2}$ & $6 \frac{1}{2}$ & $7 \frac{1}{2}$ & $8 \frac{1}{2}$ & $9 \frac{1}{2}$ \\
\hline Means & $\left.2 . \frac{1}{8}\right)$ & $\left(10 . \frac{1}{8}\right)$ & 13.2 & 16.7 & 16.2 & 16.7 & 17.6 \\
\hline S Above & 2 & 6 & 7 & 6 & 7 & 8 & 6 \\
\hline S Below & 7 & 4 & 3 & 4 & 3 & 2 & 4 \\
\hline
\end{tabular}


demonstrated, indicating that there was one point on the curve after which there was a significant change in the rate of improvement in performance. Upon visual inspection of the curve (see Figure 1), it appeared that age six-years, six-months was the point after which there was a significant decrease in rate of gain in test performance. Linear and quadratic trends together accounted for 99 per cent of the variance in scores. Other changes in rate of gain did not represent significant deviations (see Table III).

In order to analyze the comparative difficulty of the tasks to explain differences and similarities, the data were divided into two groups: scores on the Difference items and scores on the Similarity items (see Figure 2 and Table IV). Upon visual inspection, the curve representing the mean number of Difference items answered appropriately by each age group differed from the curve representing the mean number of Similarity items answered appropriately by each age group. Despite the apparent fluctuations along both curves, trend analysis indicated that 69 per cent of the variance in score on the Difference items and 68 per cent of the variance in the score on the similarity items was explained by linear trend. In addition, significant quadratic trends were demonstrated for both groups of data, accounting for 24 per cent and 23 per cent of the variance in scores among the Difference and similarity items respectively (see Tables V and VI). Again six-years, six-months appeared to be the 
TABIE III
ANALYSES OF VARIANCE AND TREND ON THE EFFECT
OF AGE ON PERFORMANCE ON THE ENTIRE TEST ACROSS SEVEN AGE GROUPS

ANALYSIS OF VARIANCE

\begin{tabular}{|cccccc|}
\hline Source & SS & df & ms & F & $p$ \\
\hline Age & 1634.43 & 6 & 272.40 & 20.77 & $<.01$ \\
$\begin{array}{c}\text { Experimental } \\
\text { Error } \\
\text { Total }\end{array}$ & 734.56 & 56 & 13.11 & -- & -- \\
& 2368.99 & 62 & - & -- & -- \\
\hline
\end{tabular}

ANALYSIS OF TREND

\begin{tabular}{|ccc|}
\hline Trend & F & z. Variance \\
\hline Iinear & $97.65^{*}$ & $78 \%$ \\
Quadratic & $25.63 *$ & $21 \%$ \\
Cubic & 3.39 (NS) & - \\
Quartic & $.07(\mathrm{NS})$ & - \\
\hline
\end{tabular}

${ }^{*} p<.01$ 


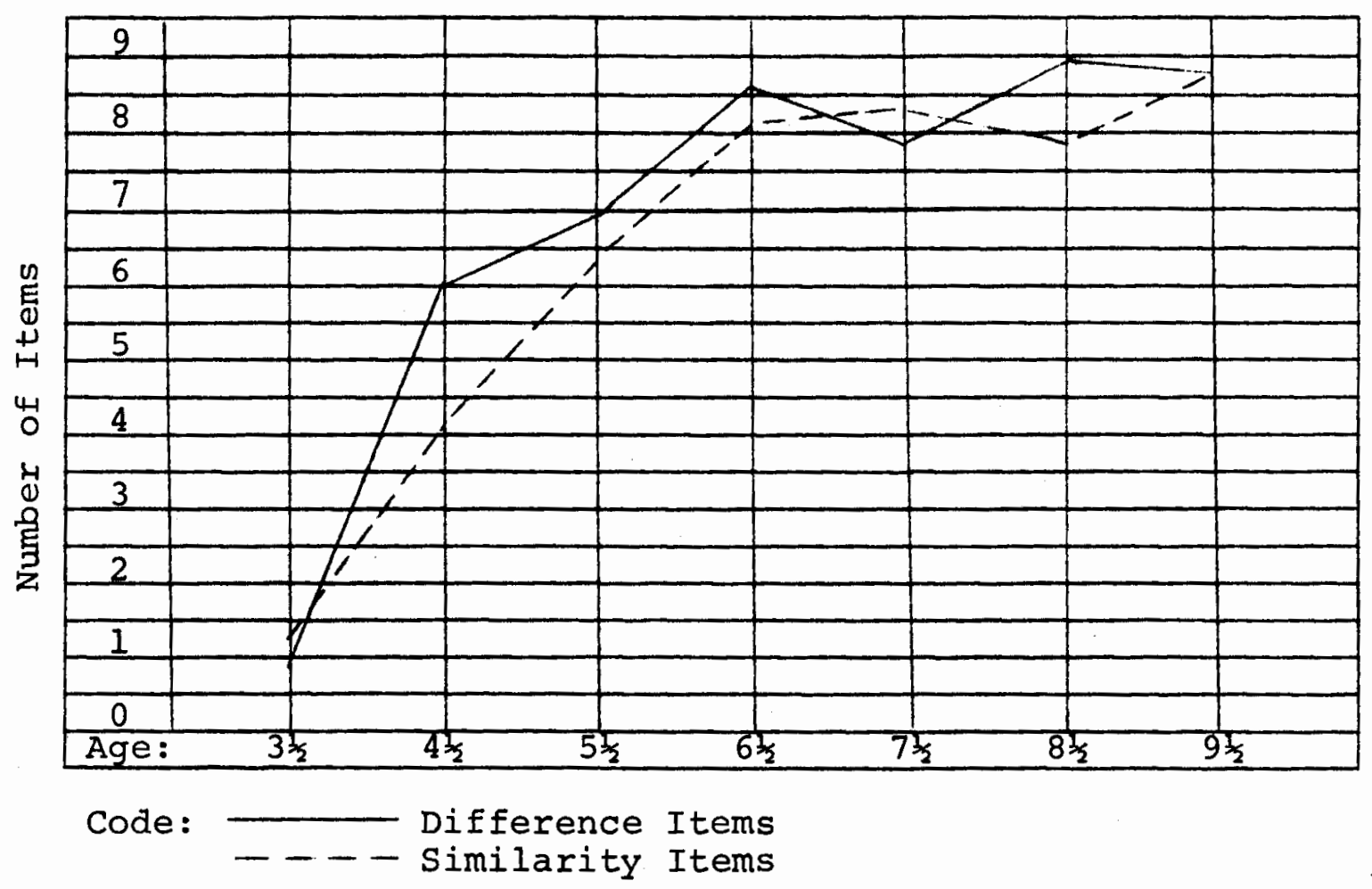

Figure 2. Comparison of mean number of items answered appropriately on Difference items and Similarity items by age group.

TABLE IV

GROUP MEANS, CORRESPONDING PERCENTAGES, AND NUMBER OF SUBJECTS ABOVE AND BELOW MEANS ON DIFFERENCE AND SIMILARITY ITEMS

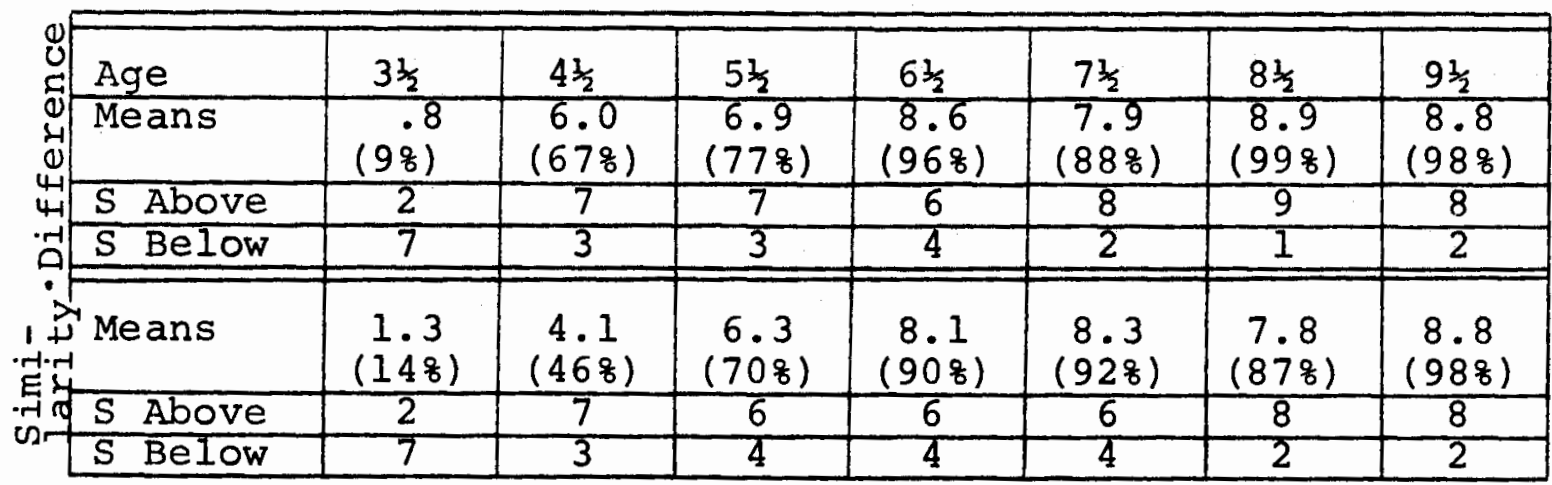


TABLE V

ANALYSES OF VARIANCE AND TREND ON THE EFFECT OF AGE

ON PERFORMANCE ON THE DIFFERENCE ITEMS

ACROSS SEVEN AGE GROUPS

ANALYSIS OF VARIANCE

\begin{tabular}{|cccccc|}
\hline Source & SS & df & ms & F & p \\
\hline Age & 452.64 & 6 & 75.44 & 20.55 & $<.01$ \\
$\begin{array}{l}\text { Experimental } \\
\text { Error }\end{array}$ & 205.78 & 56 & 3.67 & -- & -- \\
Total & 658.42 & 62 & -- & -- & -- \\
\hline
\end{tabular}

ANALYSIS OF TREND

\begin{tabular}{|ccc|}
\hline Trend & F & \& Variance \\
\hline Linear & $84.77^{*}$ & $69 \%$ \\
Quadratic & $29.07 *$ & $24 \%$ \\
Cubic & 6.18 (NS) & -- \\
Quartic & .99 (NS) & -- \\
\hline
\end{tabular}

$\star_{p}<.01$ 
TABLE VI

ANALYSES OF VARIANCE AND TREND ON THE EFFECT OF AGE

ON PERFORMANCE ON THE SIMIIARITY ITEMS

ACROSS SEVEN AGE GROUPS

ANALYSIS OF VARIANCE

\begin{tabular}{|cccccc|}
\hline Source & SS & df & ms & F & p \\
\hline Age & 427.55 & 6 & 71.25 & 41.18 & $<.01$ \\
$\begin{array}{l}\text { Experimental } \\
\text { Error } \\
\text { Total }\end{array}$ & 97.00 & 56 & 1.73 & -- & -- \\
& 524.55 & 62 & - & -- & -- \\
\hline
\end{tabular}

ANALYSIS OF TREND

\begin{tabular}{|ccc|}
\hline Trend & F & \% Variance \\
\hline Linear & $186.46 *$ & $68 \%$ \\
Quadratic & $56.15 *$ & $23 \%$ \\
Cubic & $10.29 *$ & $4 \%$ \\
Quartic & $6.31(\mathrm{NS})$ & -- \\
$*$ P 5.01 & & \\
\hline
\end{tabular}


point after which there was a significant decrease in the rate of gain in scores on both parts of the test. Other changes in rate of gain were not significant.

A comparison of the performance on Difference items and similarity items at each age group revealed higher mean scores on the Difference items at four of the seven age groups (see Figure 2). At two of the seven age groups, mean scores on the Similarity items were higher than on the Difference items. However, according to a series of $t$ tests for related measures at each of the six age groups, the differences in mean scores were not significant at the .05 level of confidence. Additionally, there was no difference in the mean scores at the nine-years, six-months age group. In order to assess the influence of stimuli on test performance, the data were divided into three groups: scores on the Object items, the Picture items, and the Word items without visual referents (see Figure 3 and Table VII). According to analyses of trend, linear and quadratic trends alone accounted for 92 per cent, 96 per cent, and 97 per cent of the variance in scores among the object, Picture, and word items, respectively (see Tables VIII, IX, and X). That is to say, at only one point along each curve was there a significant change in the rate of gain in score. Again this point appeared to be at the six-years, six-months age group. 


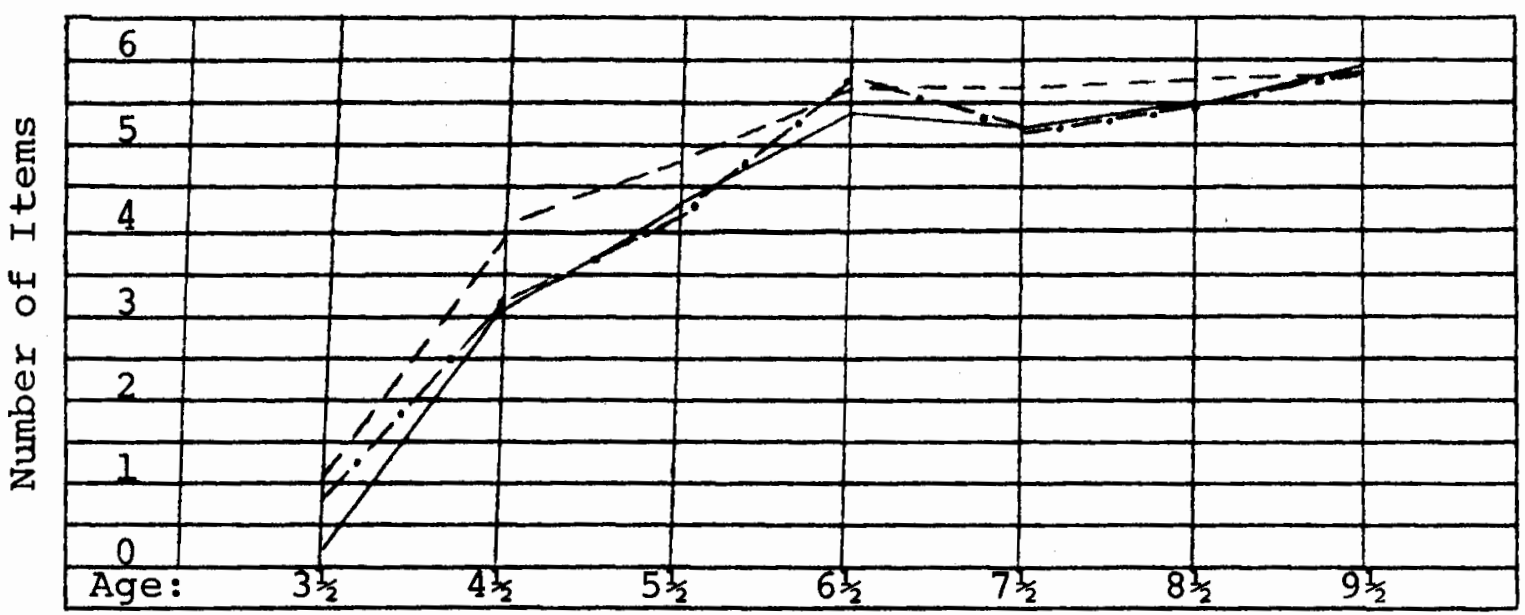

Code: - object Items

- - - Picture Items

...... Word Items

Figure 3. Comparison of mean number of items answered appropriately on object, Picture, and word Items by age group.

TABLE VII

GROUP MEANS, CORRESPONDING PERCENTAGES, AND NUMBER OF SUBJECTS ABOVE AND BELOW MEANS ON OBJECT, PICTURE, AND WORD ITEMS

\begin{tabular}{|c|c|c|c|c|c|c|c|}
\hline Age & $3 \frac{1}{2}$ & $4 \frac{1}{2}$ & $5 \frac{1}{3}$ & $6 \frac{1}{2}$ & $7 \frac{1}{2}$ & $8 \frac{1}{2}$ & $9 \frac{1}{2}$ \\
\hline Mean & $\begin{array}{r}.3 \\
(6 \%)\end{array}$ & $\begin{array}{c}3.1 \\
(578)\end{array}$ & $\begin{array}{c}4.3 \\
(728)\end{array}$ & $\begin{array}{c}5.4 \\
(908)\end{array}$ & $\begin{array}{c}5.3 \\
(88 \%)\end{array}$ & $\begin{array}{c}5.5 \\
(928)\end{array}$ & $\begin{array}{c}5.9 \\
(988)\end{array}$ \\
\hline Above & 1 & 4 & 6 & 6 & 5 & 7 & 9 \\
\hline Below & 8 & 6 & 4 & 4 & 5 & 3 & 1 \\
\hline Mean & $\begin{array}{c}1.0 \\
(17 \%)\end{array}$ & $\begin{array}{c}3.8 \\
(638)\end{array}$ & $\begin{array}{c}4.7 \\
(788)\end{array}$ & $\begin{array}{c}5.6 \\
(938)\end{array}$ & $\begin{array}{c}5.6 \\
(93 \%)\end{array}$ & $\begin{array}{c}5.7 \\
(958)\end{array}$ & $\begin{array}{c}5.9 \\
(98 \%)\end{array}$ \\
\hline Above & 2 & 6 & 7 & 7 & 8 & 9 & 9 \\
\hline Below & 7 & 4 & 3 & 3 & 2 & $I$ & 1 \\
\hline Mean & $\begin{array}{c}.8 \\
(13 \%)\end{array}$ & $\begin{array}{c}3.2 \\
(538)\end{array}$ & $\begin{array}{c}4.2 \\
(70 \%)\end{array}$ & $\begin{array}{c}5.7 \\
(958)\end{array}$ & $\begin{array}{c}5.3 \\
(88 \%)\end{array}$ & $\begin{array}{c}5.5 \\
(928)\end{array}$ & $\begin{array}{c}5.8 \\
(978)\end{array}$ \\
\hline Above & $\overline{3}$ & 3 & 6 & 7 & 5 & 8 & 8 \\
\hline Below & 6 & 7 & 4 & 3 & 5 & 2 & 2 \\
\hline
\end{tabular}


TABLE VIII

ANALYSES OF VARIANCE AND TREND ON THF EFFECT OF AGE ON PERFORMANCE ON THE OBJECT ITEMS

ACROSS SEVEN AGE GROUPS

ANALYSIS OF VARIANCE

\begin{tabular}{|cccccc|}
\hline Source & SS & df & ms & F & p \\
\hline Age & 207.87 & 6 & 34.64 & 19.10 & $<.01$ \\
$\begin{array}{c}\text { Experimental } \\
\text { Error } \\
\text { Total }\end{array}$ & 101.56 & 56 & 1.81 & -- & $\ldots-$ \\
& 309.43 & 62 & -- & $-\ldots$ & -- \\
\hline
\end{tabular}

ANALYSIS OF TREND

\begin{tabular}{|ccc|}
\hline Trend & F & \% Variance \\
\hline Linear & $169.44 *$ & $82 \%$ \\
Quadratic & $21.12 *$ & $10 \%$ \\
Cubic & 6.39 (NS) & - \\
Quartic & .01 (NS) & - \\
\hline
\end{tabular}

${ }^{*} \mathrm{p}<.01$ 
TABLE IX

ANALYSES OF VARIANCE AND TREND ON THE EFFECT OF AGE ON PERFORMANCE ON THE PICTURE ITEMS

ACROSS SEVEN AGE GROUPS

ANALYSIS OF VARIANCE

\begin{tabular}{|cccccc|}
\hline Source & SS & df & ms & F & p \\
\hline Age & 168.10 & 6 & 28.02 & 16.12 & $<.01$ \\
$\begin{array}{l}\text { Experimental } \\
\text { Error } \\
\text { Total }\end{array}$ & 97.33 & 56 & 1.74 & -- & $\ldots-$ \\
\hline
\end{tabular}

ANAIYSIS OF TREND

\begin{tabular}{|ccc|}
\hline Trend & F & \& Variance \\
\hline Linear & $71.45 *$ & 748 \\
Quadratic & $21.20 *$ & 228 \\
Cubic & 3.07 (NS) & - \\
Quartic & .01 (NS) & - \\
\hline * 6.01 & & \\
\hline
\end{tabular}


TABLE X

ANALYSES OF VARIANCE AND TREND ON THE EFFECT OF AGE ON PERFORMANCE ON THE WORD ITEMS ACROSS SEVEN AGE GROUPS

ANALYSIS OF VARIANCE

\begin{tabular}{|cccccc|}
\hline Source & SS & df & ms & F & p \\
\hline Age & 184.76 & 6 & 30.79 & 17.10 & $<.01$ \\
$\begin{array}{c}\text { Experimental } \\
\text { Error } \\
\text { Total }\end{array}$ & 100.89 & 56 & 1.80 & $-\ldots$ & - \\
& 285.65 & 62 & -- & -- & - \\
\hline
\end{tabular}

ANALYSIS OF TREND

\begin{tabular}{|ccc|}
\hline Trend & F & \& Variance \\
\hline Linear & $78.75 *$ & 778 \\
Quadratic & $20.49 *$ & 208 \\
Cubic & $1.74(\mathrm{NS})$ & - \\
Quartic & $.55(\mathrm{NS})$ & - \\
\hline
\end{tabular}

${ }^{*} p<.01$ 
A comparison at each age group of the mean scores obtained on the Object, Picture, and word items revealed that mean scores on the object and word items were essentially the same at all age groups (see Figure 3 and Table VII). The mean scores were slightly higher on the Picture items than on the object and word items at six of the seven age groups. The results of a series of $t$ tests for related measures revealed that these differences among the mean scores on the three stimulus types were not sifnificant at the .05 level of confidence.

In order to account for differences in individual performances within each age group, the raw data were reorganized so as to present the number of subjects at each age group who appropriately answered a sufficient percentage of the items to demonstrate the ability to verbally explain differences and similarities. The researcher designated 75 per cent to be a sufficient percentage of items passed. At this level of performance, the subjects were performing above the level of chance. The researcher decided that 100 per cent accuracy was not necessary to demonstrate ability to perform the task, especially in light of the fact that without an item analysis, there was no assurance that each item tested what it was purported to test. Seventy-five per cent accuracy was the point at which the subjects operationally appeared to be able to perform the task.

On the test as a whole (see Figure 4 and Table XI), the 


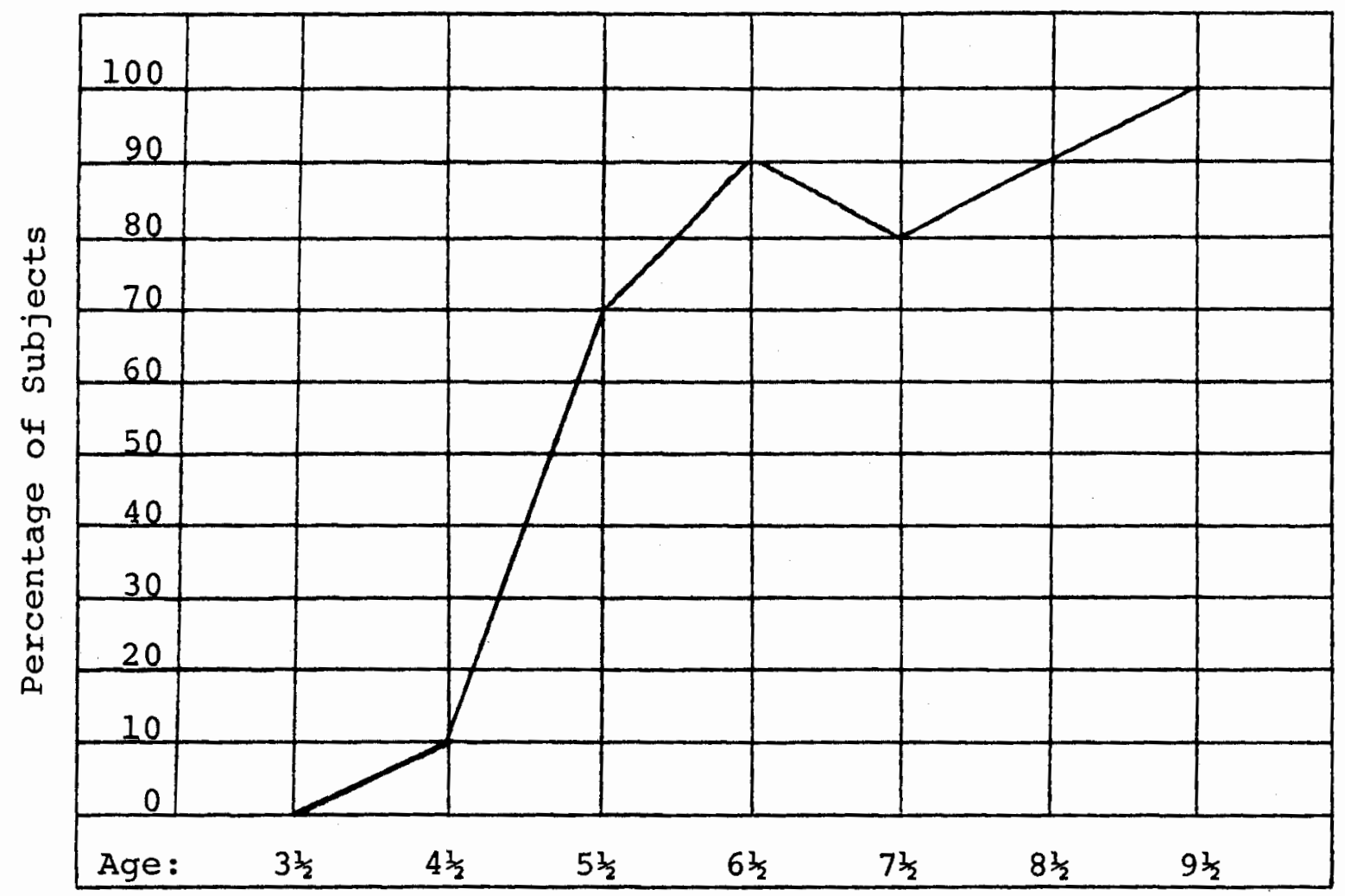

Figure 4. Percentage of subjects in each age group who answered at least 75 per cent ( 14 items) of total items appropriately.

TABIE XI

PERCENTAGE OF SUBJECTS IN EACH AGE GROUP WHO ANSWERED AT LEAST 75 PER CENT OF TOTAL ITEMS APPROPRIATELY

\begin{tabular}{|l|l|l|l|l|l|l|l|}
\hline Age & $3 \frac{1}{2}$ & $4 \frac{1}{2}$ & $5 \frac{1}{2}$ & $6 \frac{1}{2}$ & $7 \frac{1}{2}$ & $8 \frac{1}{2}$ & $9 \frac{1}{2}$ \\
\hline Percentage & 08 & 108 & 708 & 908 & 808 & 908 & 1008 \\
\hline
\end{tabular}


greatest increase in number of children able to answer at least 75 per cent of the items occurred between four-years, six-months and five-years, six-months. At these ages the number of children who appropriately answered at least 75 per cent of the items increased from one child ( 10 per cent) to seven children (70 per cent).

A comparison of the performances on Difference items and on similarity items revealed that more children answered at least 75 per cent of the Difference items appropriately than answered at least 75 per cent of the similarity items appropriately at four of the seven age groups (see Figure 5 and Table XII). The difference at four-years, six-months was most noticeable. In light of the absence of significant differences between group mean scores on Difference and Similarity items, the significance of these apparent differences is unlikely. By six-years, six-months, 10 (100 per cent) and 9 (90 per cent) of the children answered at least 75 per cent of the Difference and Similarity items appropriately, respectively.

Upon visual inspection, there appeared to be no significant differences among the three stimulus types (Object, Picture, and word items) with respect to the number of children in each age group who answered at least 75 per cent of the items appropriately (see Figure 6 and Table XIII). By six-years, six-months, 8 ( 80 per cent), 9 (90 per cent), and 10 (100 per cent) of the children answered at least 75 per 


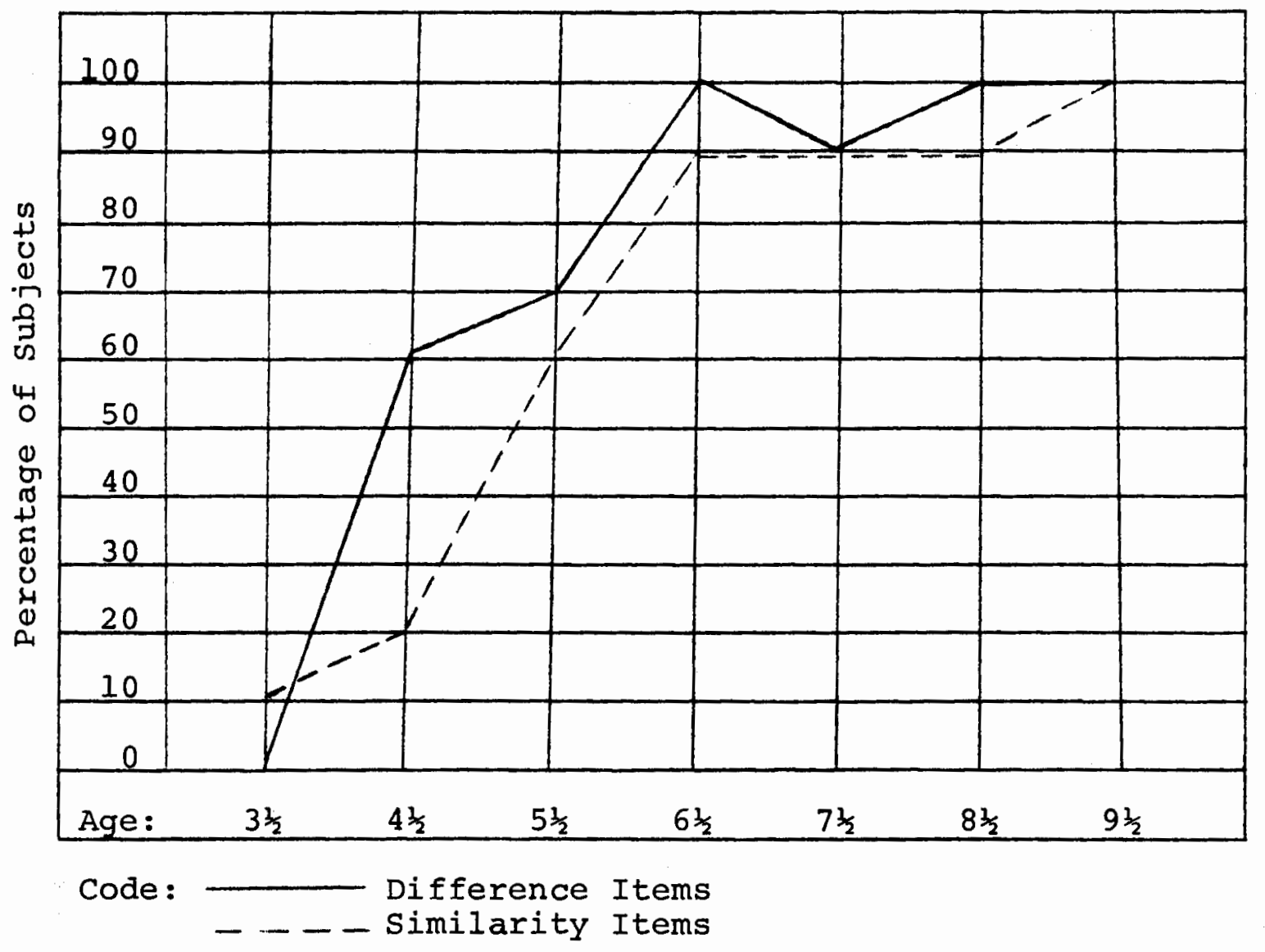

Figure 5. Percentage of subjects in each age group who answered at least 75 per cent $(7$ items) of Difference and of Similarity items appropriately.

TABLE XII

PERCENTAGE OF SUBJECTS IN EACH AGE GROUP WHO ANSWERED AT LEAST 75 PER CENT OF DIFFERENCE AND SIMILARITY ITEMS APPROPRIATELY

\begin{tabular}{|l|c|c|c|c|c|c|c|}
\hline Age & $3 \frac{1}{2}$ & $4 \frac{1}{2}$ & $5 \frac{1}{2}$ & $6 \frac{1}{2}$ & $7 \frac{1}{2}$ & $8 \frac{1}{2}$ & $9 \frac{1}{2}$ \\
\hline Items: & & & & & & & \\
\hline Difference & $0 \frac{8}{8}$ & $60 \%$ & $70 \%$ & $100 \frac{8}{8}$ & $90 \%$ & $100 \frac{8}{8}$ & $100 \frac{8}{8}$ \\
\hline Similarity & $11 \frac{8}{8}$ & 208 & 608 & $90 \frac{8}{8}$ & $90 \%$ & $90 \frac{8}{8}$ & $100 \frac{8}{8}$ \\
\hline
\end{tabular}




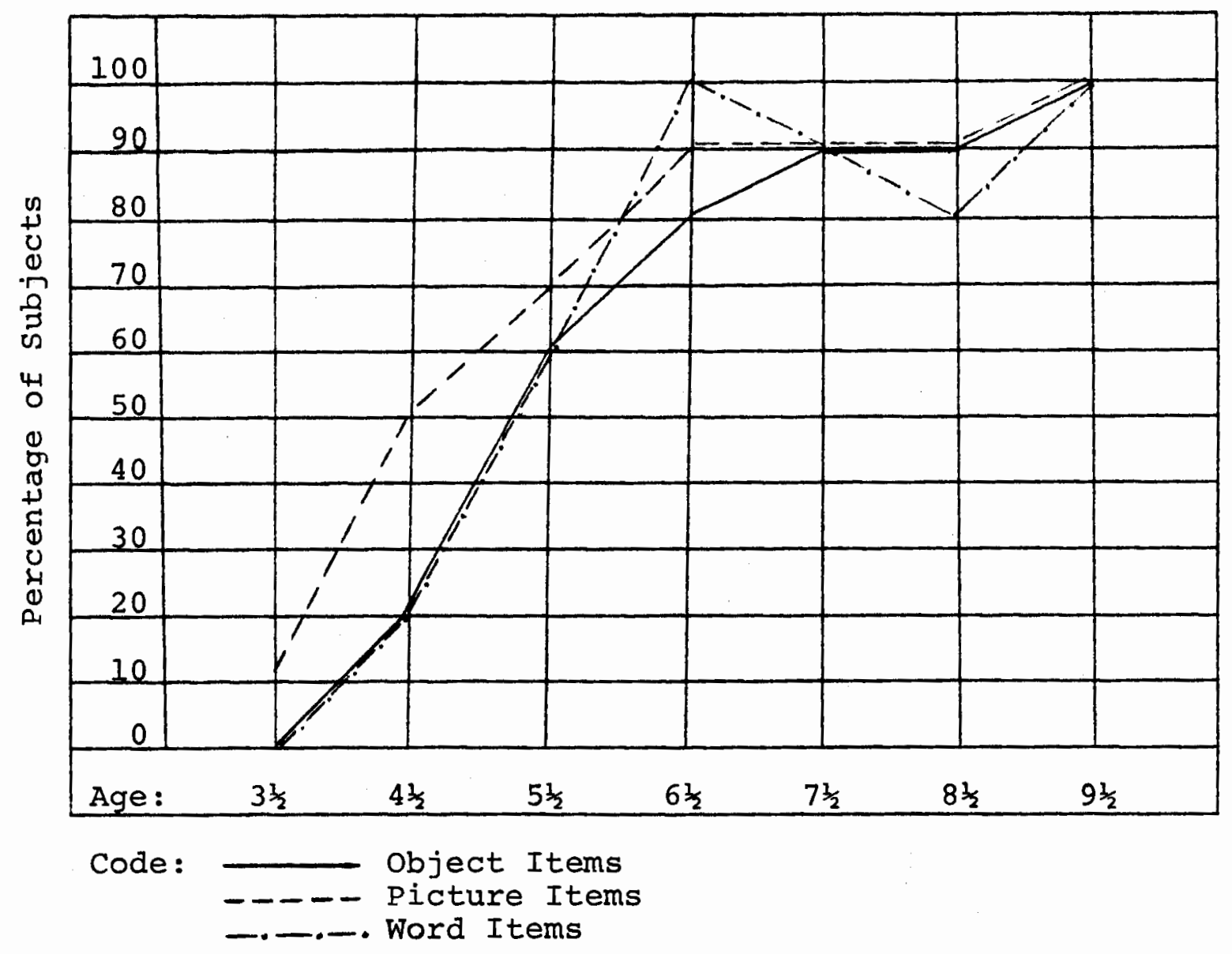

Figure 6. Percentage of subjects in each age group who answered at least 75 per cent ( 5 items) of object, Picture, and Word items appropriately.

TABLE XIII

PERCENTAGE OF SUBJECTS IN EACH AGE GROUP WHO ANSWERED AT LEAST 75 PER CENT OF OBJECT, PICTURE, AND WORD ITEMS APPROPRIATELY

\begin{tabular}{|l|c|c|c|c|c|c|c|}
\hline Age & $3 \frac{1}{2}$ & $4 \frac{1}{2}$ & $5 \frac{1}{2}$ & $6 \frac{1}{2}$ & $7 \frac{1}{2}$ & $8 \frac{1}{2}$ & $9 \frac{1}{2}$ \\
\hline Items: & & & & & & & \\
\hline Object & $0 \frac{8}{8}$ & 208 & 608 & 808 & 908 & 908 & 1008 \\
\hline Picture & 118 & 508 & 708 & 908 & 908 & 908 & 1008 \\
\hline Word & 08 & 208 & 608 & 1008 & 908 & 808 & 1008 \\
\hline
\end{tabular}


cent of the object, Picture, and Word items appropriately, respectively.

II. MEAN NUMBER OF APPROPRIATE RESPONSES PER ITEM

The number of appropriate responses per item increased significantly (beyond the .05 level of confidence) between successive age groups from three-years, six-months to sixyears, six-months (see Table XIV). Beyond six-years, sixmonths, the differences demonstrated in mean number of appropriate responses per item for each age group were not significant at the .05 level of confidence. Furthermore, the difference between the mean number of appropriate responses per item for the six-years, six-months age group and for the nine-years, six-months age group was not significant. In each case, $t$ test for related measures was used (see Table XV)

III. CLASSIFICATION OF APPROPRIATE RESPONSES

Because of the nature of the data in this portion of the study, a descriptive method was used rather than conventional statistical procedures.

TABLE XIV

MEAN NUMBER OF APPROPRIATE RESPONSES PER ITEM BY AGE GROUP

\begin{tabular}{|l|c|c|c|c|c|c|c|}
\hline Age & $3 \frac{1}{2}$ & $4 \frac{1}{2}$ & $5 \frac{1}{2}$ & $6 \frac{1}{2}$ & $7 \frac{1}{3}$ & $8 \frac{1}{2}$ & $9 \frac{1}{2}$ \\
Means & .12 & .57 & .79 & 1.01 & 1.07 & 1.40 & 1.25 \\
\hline
\end{tabular}


TABLE XV

MEANS, STANDARD DEVIATIONS, AND T-VAIUES FOR MEAN NUMBER OF APPROPRIATE RESPONSES PER ITEM AT SUCCESSIVE AGE GROUPS AND BETWEEN SIX-YEARS, SIX-MONTHS AND NINE-YEARS, SIX-MONTHS (IV-VI)

\begin{tabular}{|c|c|c|c|}
\hline Age Interval & Mean Scores & SD & t-Value \\
\hline$I$ & & & $-4.29 *$ \\
\hline $\begin{array}{l}\text { Three-years, six-months } \\
\text { Four-years, six-months }\end{array}$ & $\begin{array}{r}.12 \\
.57\end{array}$ & $\begin{array}{l}.22 \\
.23\end{array}$ & \\
\hline II & & & $-1.86 *$ \\
\hline $\begin{array}{l}\text { Four-years, six-months } \\
\text { Five-years, six-months }\end{array}$ & $\begin{array}{l}.57 \\
.79\end{array}$ & $\begin{array}{l}.23 \\
.29\end{array}$ & \\
\hline III & & & $-2.11 *$ \\
\hline $\begin{array}{l}\text { Five-years, six-months } \\
\text { six-years, six-months }\end{array}$ & $\begin{array}{r}.79 \\
1.01\end{array}$ & $\begin{array}{l}.29 \\
.15\end{array}$ & \\
\hline IV & & & -.32 \\
\hline $\begin{array}{l}\text { Six-years, six-months } \\
\text { Seven-years, six-months }\end{array}$ & $\begin{array}{l}1.01 \\
1.07\end{array}$ &. .15 & \\
\hline V & & & -1.10 \\
\hline $\begin{array}{l}\text { Seven-years, six-months } \\
\text { Eight-years, six-months }\end{array}$ & $\begin{array}{l}1.07 \\
1.40\end{array}$ & $\begin{array}{l}.55 \\
.76\end{array}$ & \\
\hline VI & & & .53 \\
\hline $\begin{array}{l}\text { Eight-years, six-months } \\
\text { Nine-years, six-months }\end{array}$ & $\begin{array}{l}1.40 \\
1.25\end{array}$ & $\begin{array}{l}.76 \\
.46\end{array}$ & \\
\hline$I V-V I$ & & & -1.55 \\
\hline $\begin{array}{l}\text { Six-years, six-months } \\
\text { Nine-years, six-months }\end{array}$ & $\begin{array}{l}1.01 \\
1.25\end{array}$ & $\begin{array}{l}.15 \\
.46\end{array}$ & \\
\hline
\end{tabular}

$\star p<.05$ 
Looking at the test as a whole (see Figure 7 and Table XVI) the greatest percentage of appropriate responses across all ages was Type II-Functional responses. The smallest percentage of appropriate responses across all ages was Type IIINominal responses. Type I-Perceptible responses maintained a level between Type II and Type III responses across all ages.

While the curves which represent Type I and Type II responses were uneven across age, the Type III-Nominal responses displayed a gradually rising, linear trend. At four-years, six-months and at eight-years, six-months, the percentages of Type I and Type II responses were nearly equal, around 50 per cent and 45 per cent, respectively. Between these two age points, the percentage of Type I responses decreased to a low of 23 per cent at six-years, six-months, as the percentage of Type II responses increased to a high of 65 per cent at six-years, six-months.

At three-years, six-months, the relative percentages of the three response types was most disproportionate. Also at this age the mean number of appropriate responses was low, so the reliability of the percentage of response types at this age is poor. As the percentage of Type III responses increased with age the relative percentages of the three response types became less disproportionate.

The distribution of appropriate responses among the three response types on the Difference items varied from the distribution of response types on the similarity items. The 


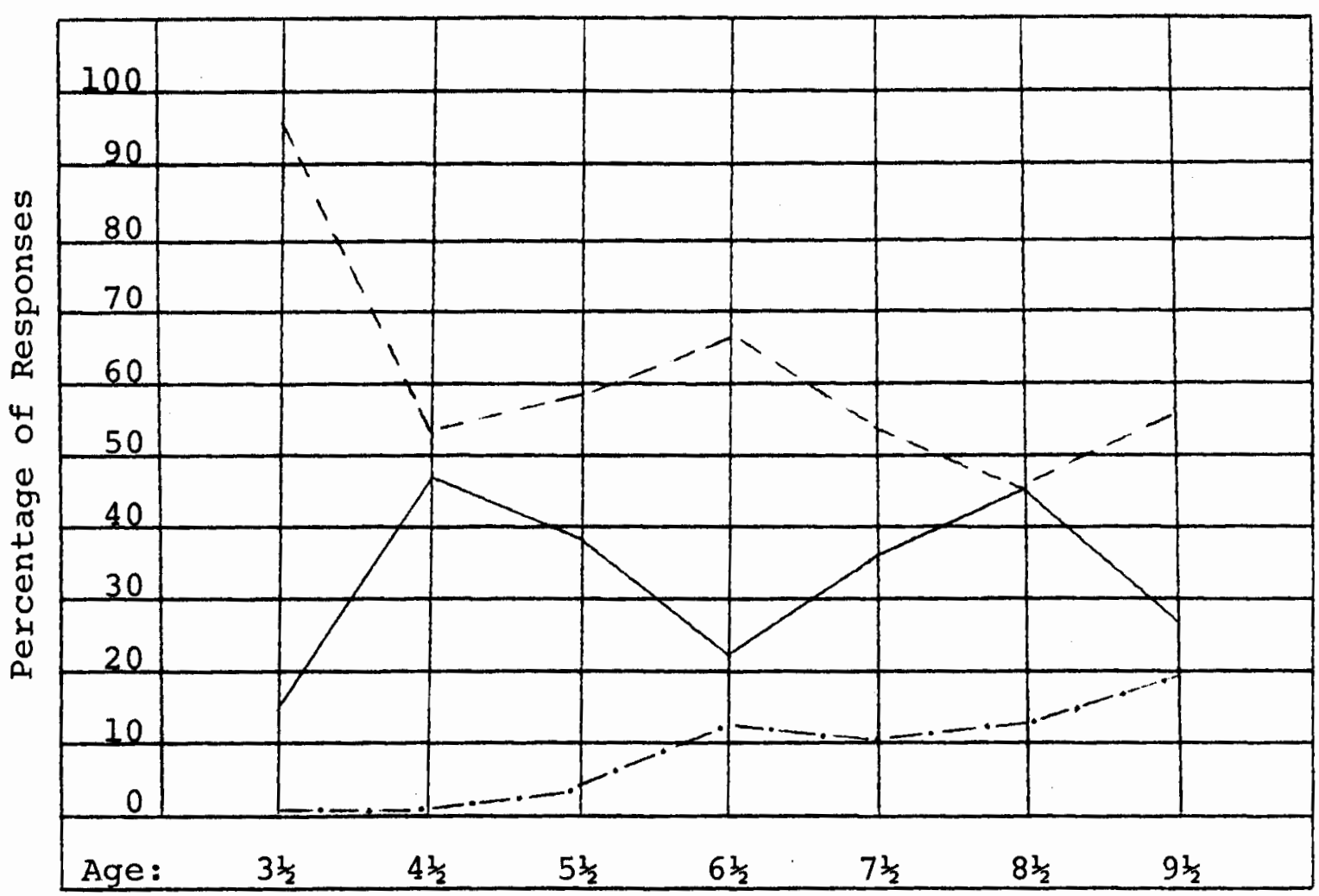

$$
\begin{aligned}
& \text { Code: } \text { Type I - Perceptible Responses } \\
& \text { - }- \text { Type II - Functional Responses } \\
& \text { - Type III - Nominal Responses }
\end{aligned}
$$

Figure 7. Relative contribution of three response types to total appropriate responses on the test as a whole across seven age groups.

TABLE XVI

PERCENTAGE OF RESPONSES IN THREE RESPONSE TYPES BY AGE GROUP

\begin{tabular}{|l|c|c|c|c|c|c|c|}
\hline Age & $3 \frac{1}{2}$ & $4 \frac{1}{2}$ & $5 \frac{1}{2}$ & $6 \frac{1}{2}$ & $7 \frac{1}{2}$ & $8 \frac{1}{2}$ & $9 \frac{1}{2}$ \\
\hline Response Type: & & & & & & & \\
\hline Type I & $5 \%$ & 478 & $38 \%$ & $23 \%$ & 358 & 448 & 268 \\
\hline Type II & $95 \%$ & 538 & 598 & $65 \%$ & 558 & 458 & $55 \%$ \\
\hline Type III & 08 & 08 & 38 & 128 & $10 \%$ & 118 & 198 \\
\hline
\end{tabular}


younger children used slightly more Type I-Perceptible responses in explanations of similarity than in explanations of difference (see Figure 8 and Table XVII). All age groups used more Type II-Function responses in explanations of difference than in explanations of similarity (see Figure 9 and Table XVIII). Furthermore in explanations of difference, there were far more Type II-Function responses than Type I-Perceptible responses at all ages; whereas in explanations of similarity, the difference in percentages of Type II-Function responses and Type I-Perceptible responses was not as great (see Figures 8 and 9). While only a small percentage of responses among all ages were Type III-Nominal responses, the percentage of Type III responses increased faster in explanations of similarity than in explanations of difference (see Figure 10 and Table XIX).

Apparently the difference in stimulus types had little effect on the response types used to explain differences and similarities. While the distribution of response types did vary among the three stimulus types, there was apparently no consistent effect (see Figures 11, 12, and 13, and Tables XX, XXI, and XXII). Slightly fewer Type I-Perceptible responses were used on the word items than on the object or picture items (see Figure 11). There was a slightly slower rate of increase in percentage of Type III-Nominal responses on object items than on Picture or Word items. 


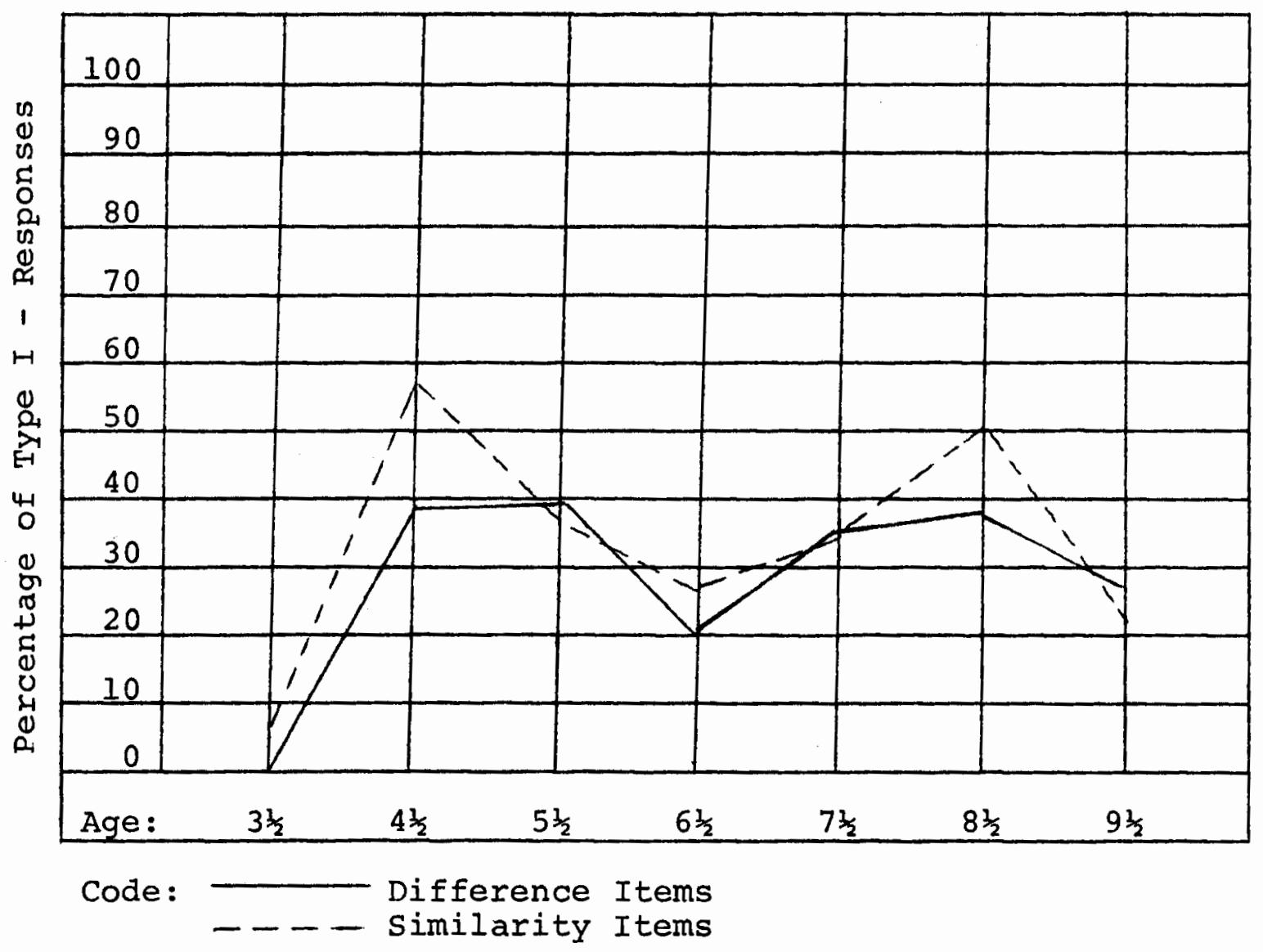

Figure 8. Comparison of the percentage of responses among Difference and Similarity items that were Type I Perceptible responses.

TABLE XVII

PERCENTAGE OF TYPE I - PERCEPTIBLE RESPONSES ON DIFFERENCE AND SIMILARITY ITEMS

\begin{tabular}{|l|c|c|c|c|c|c|c|}
\hline Age & $3 \frac{1}{2}$ & $4 \frac{1}{2}$ & $5 \frac{1}{2}$ & $6 \frac{1}{2}$ & $7 \frac{1}{2}$ & $8 \frac{1}{2}$ & $9 \frac{1}{2}$ \\
\hline Items: & & & & & & & \\
\hline Difference & $0 \frac{8}{8}$ & $39 \frac{8}{8}$ & 398 & $20 \frac{8}{8}$ & $35 \%$ & $38 \frac{8}{8}$ & $29 \%$ \\
\hline Similarity & $8 \frac{8}{8}$ & $57 \frac{8}{8}$ & $38 \%$ & $27 \frac{8}{8}$ & 348 & $50 \frac{8}{8}$ & 228 \\
\hline
\end{tabular}




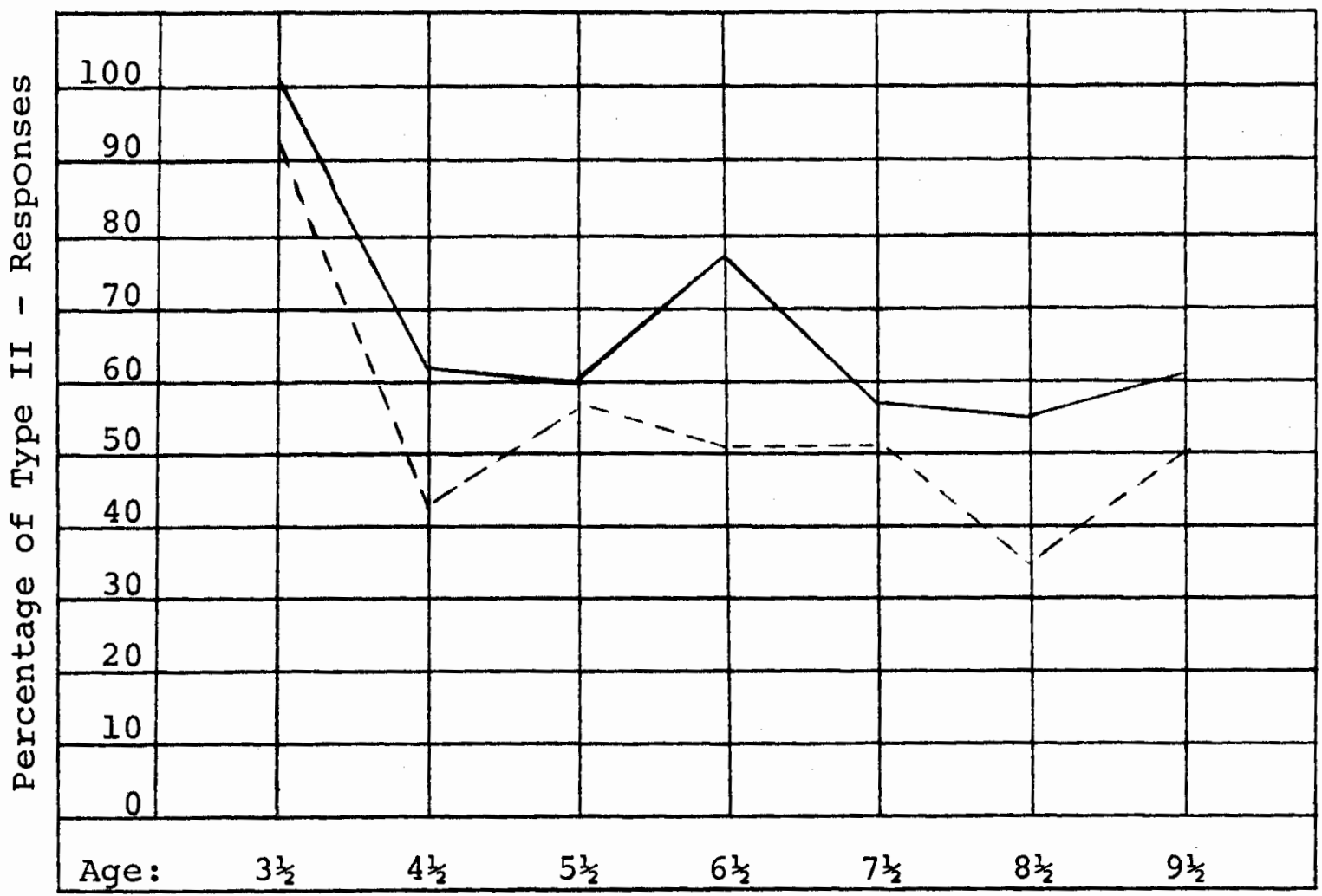

Code: Difference Items

- . - Similarity Items

Figure 9. Comparison of the percentage of responses among Difference and Similarity items that were Type II - Functional responses.

TABIE XVIII

PEERCENTAGE OF TYPE II - FUNCTIONAL RESPONSES

ON DIFFERENCE AND SIMILARITY ITEMS

\begin{tabular}{|l|c|c|c|c|c|c|c|}
\hline Age & $3 \frac{1}{2}$ & $4 \frac{1}{2}$ & $5 \frac{1}{2}$ & $6 \frac{1}{2}$ & $7 \frac{1}{2}$ & $8 \frac{1}{2}$ & $9 \frac{1}{2}$ \\
\hline Items: & & & & & & & \\
\hline Difference & $100 \%$ & $61 \%$ & $60 \%$ & $78 \%$ & $59 \%$ & 558 & 618 \\
\hline Similarity & $92 \%$ & $43 \%$ & $56 \%$ & 518 & $51 \%$ & 358 & 508 \\
\hline
\end{tabular}




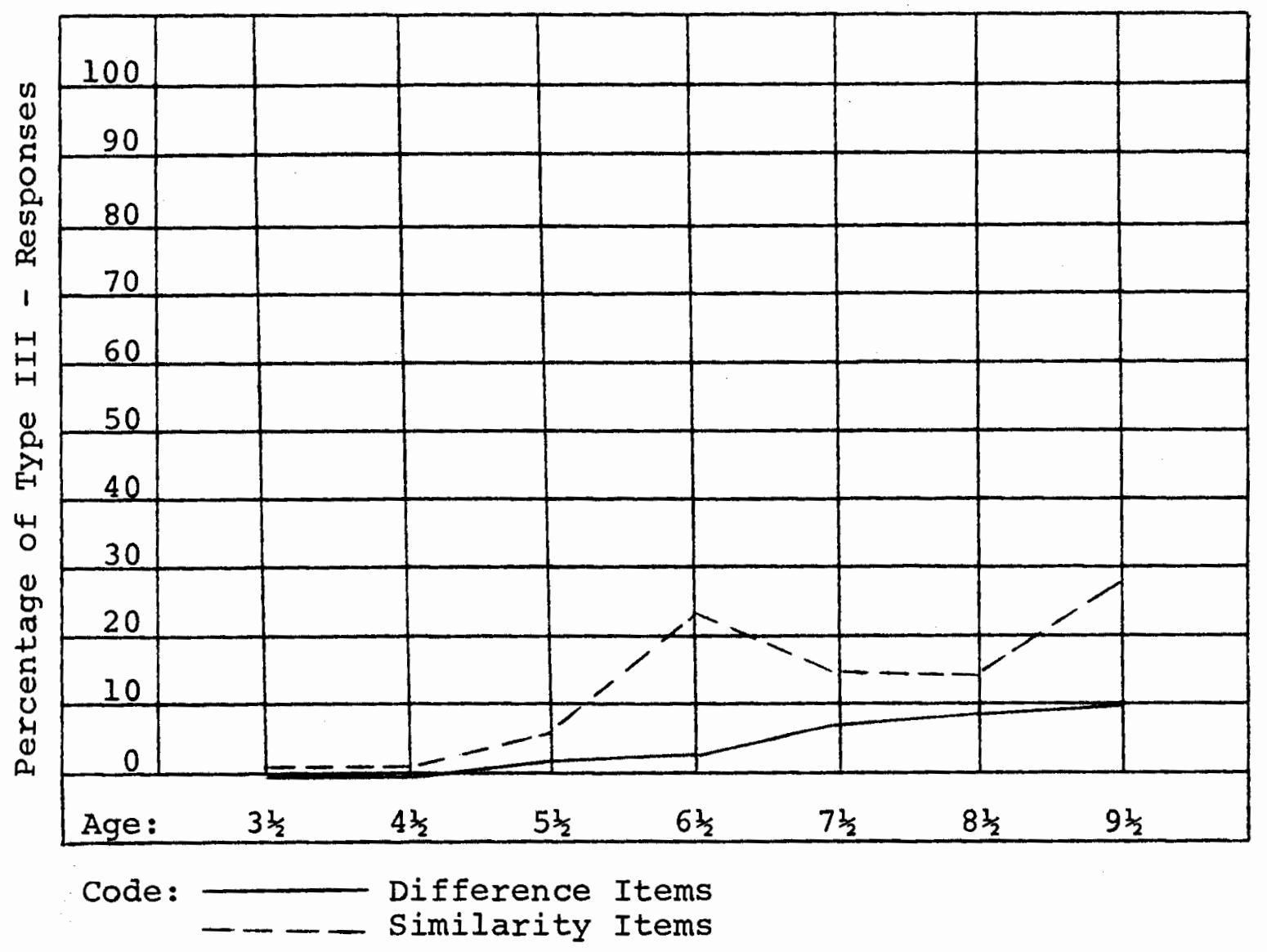

Figure 10. Comparison of the percentage of responses among Difference and Similarity items that were Type III - Nominal responses.

TABLE XIX

PERCENTAGE OF TYPE III - NOMINAL RESPONSES ON DIFFERENCE AND SIMILARITY ITEMS

\begin{tabular}{|l|c|c|c|c|c|c|c|}
\hline Age & $3 \frac{1}{2}$ & $4 \frac{1}{2}$ & $5 \frac{1}{2}$ & $6 \frac{1}{2}$ & $7 \frac{1}{2}$ & $8 \frac{1}{2}$ & $9 \frac{1}{2}$ \\
\hline Items: & & & & & & & \\
\hline Difference & $0 \frac{8}{8}$ & $0 \frac{8}{8}$ & $1 \frac{8}{8}$ & $2 \frac{8}{8}$ & $6 \frac{8}{8}$ & $7 \frac{8}{8}$ & $10 \frac{8}{8}$ \\
\hline Similarity & $0 \frac{8}{8}$ & 08 & $6 \frac{8}{8}$ & $22 \frac{8}{8}$ & $15 \frac{8}{8}$ & 158 \\
\hline
\end{tabular}




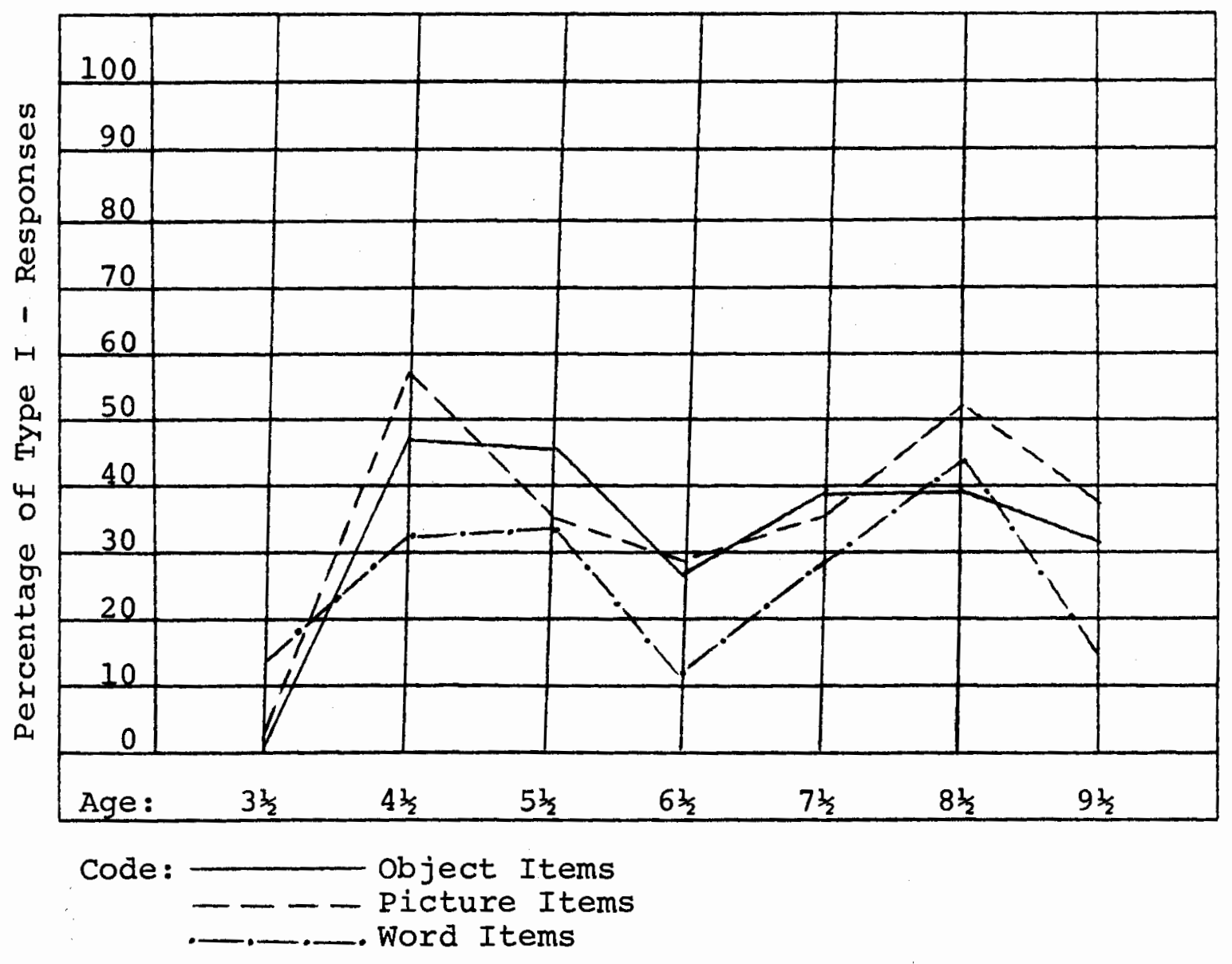

Figure 11. Comparison of the percentage of responses among object, Picture, and Word items that were Type I - Perceptible responses.

TABLE XX

PERCENTAGE OF TYPE I - PERCEPTIBLE RESPONSES ON OBJECT, PICTURE, AND WORD ITEMS

\begin{tabular}{|l|c|c|c|c|c|c|c|}
\hline Age & $3 \frac{1}{2}$ & $4 \frac{1}{2}$ & $5 \frac{1}{2}$ & $6 \frac{1}{2}$ & $7 \frac{1}{2}$ & $8 \frac{1}{2}$ & $9 \frac{1}{2}$ \\
\hline Items: & & & & & & & \\
\hline Object & 08 & 488 & 468 & 278 & 398 & 398 & 328 \\
\hline Picture & 08 & 588 & 368 & 298 & 358 & $51 \%$ & 288 \\
\hline Word & 148 & 318 & 338 & 128 & 298 & 438 & 158 \\
\hline
\end{tabular}




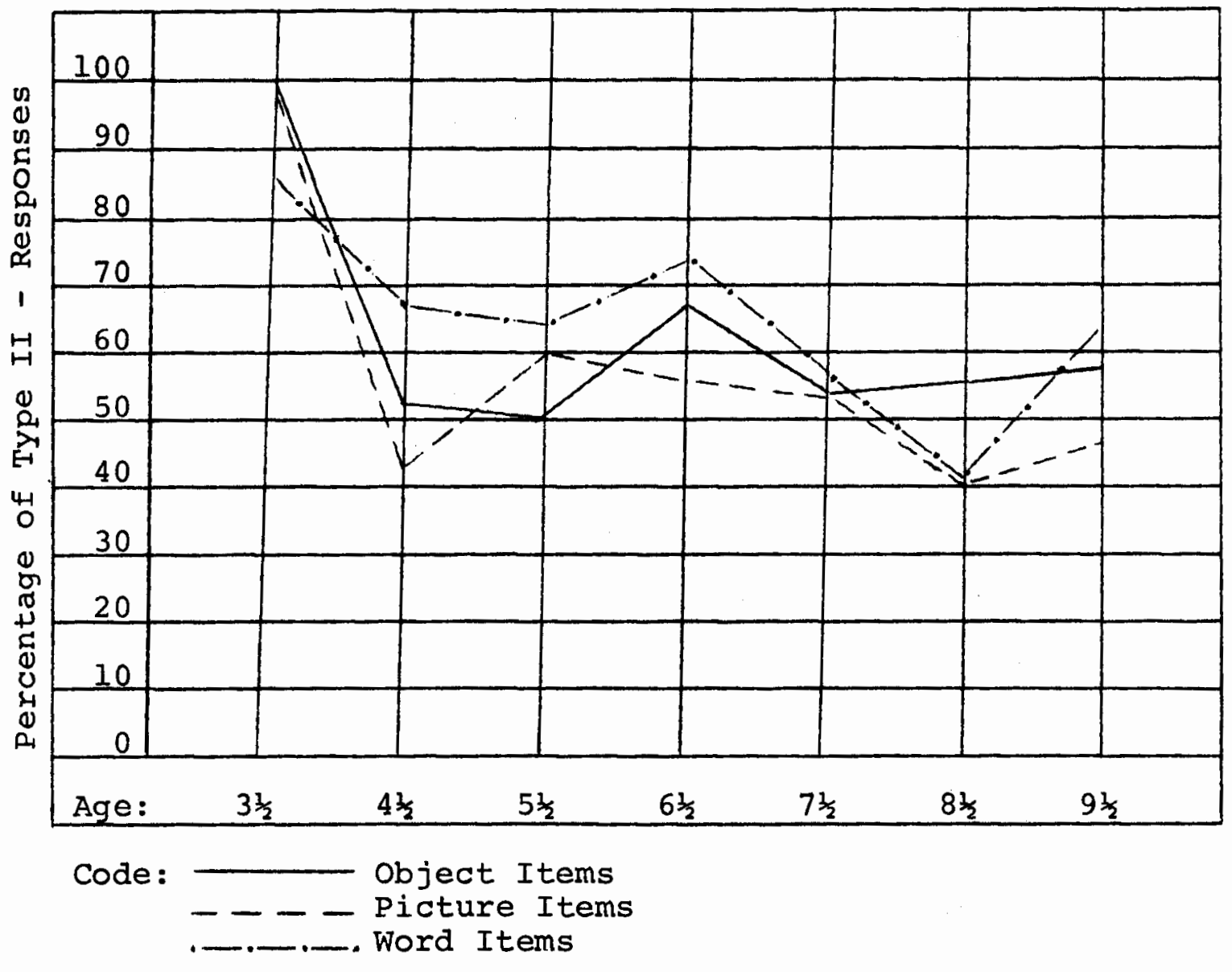

Figure 12. Comparison of the percentage of responses among object, Picture, and Word items that were Type II - Functional responses.

TABLE XXI

PERCENTAGE OF TYPE II - FUNCTIONAI RESPONSES ON OBJECT, PICTURE, AND WORD ITEMS

\begin{tabular}{|l|c|c|c|c|c|c|c|}
\hline Age & $3 \frac{1}{2}$ & $4 \frac{1}{2}$ & $5 \frac{1}{2}$ & $6 \frac{1}{2}$ & $7 \frac{1}{2}$ & $8 \frac{1}{2}$ & $9 \frac{1}{2}$ \\
\hline Items: & & & & & & & \\
\hline Object & $100 \%$ & $52 \frac{8}{8}$ & $50 \%$ & $66 \%$ & $54 \%$ & $55 \%$ & $56 \frac{8}{8}$ \\
\hline Picture & $100 \%$ & 428 & $60 \%$ & $56 \%$ & $54 \%$ & $40 \%$ & $46 \frac{8}{8}$ \\
\hline Word & $86 \%$ & 698 & $65 \%$ & 748 & $58 \%$ & $41 \frac{8}{8}$ & $64 \frac{8}{8}$ \\
\hline
\end{tabular}




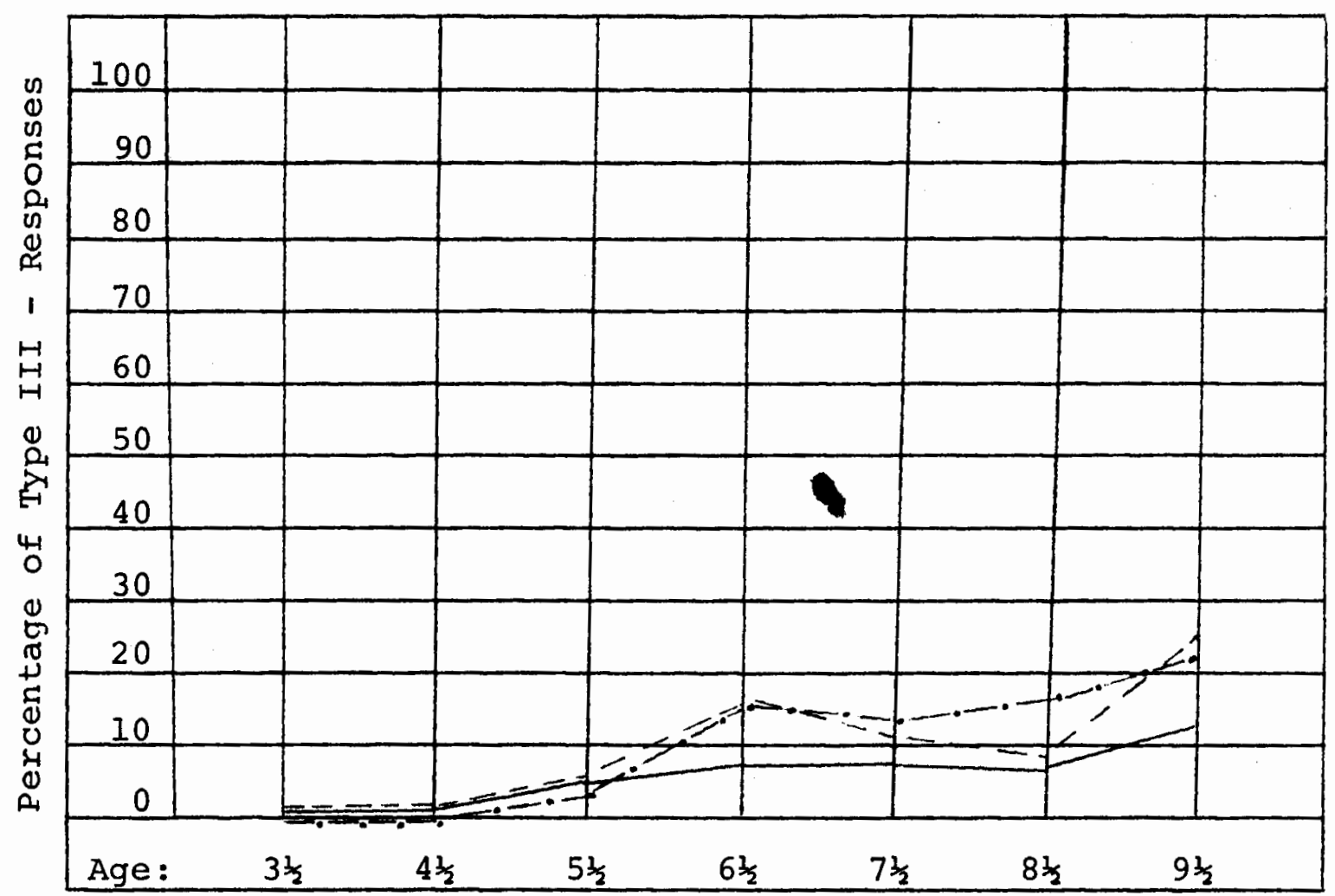

Code :

Object Items

- - - Picture Items

-...... Word Items

Figure 13. Comparison of the percentage of responses among object, Picture, and word items that were Type III - Nominal responses.

TABIE XXII

PERCENTAGE OF TYPE III - NOMINAI RESPONSES ON OBJECT, PICTURE, AND WORD ITEMS

\begin{tabular}{|l|c|c|c|c|c|c|c|}
\hline Age & $3 \frac{1}{2}$ & $4 \frac{1}{2}$ & $5 \frac{1}{2}$ & $6 \frac{1}{2}$ & $7 \frac{1}{2}$ & $8 \frac{1}{2}$ & $9 \frac{1}{2}$ \\
\hline Items: & & & & & & & \\
\hline Object & $0 \frac{8}{8}$ & $0 \frac{8}{8}$ & $4 \frac{8}{8}$ & $7 \%$ & $7 \%$ & $6 \frac{8}{8}$ & 128 \\
\hline Picture & 08 & $0 \frac{8}{8}$ & $4 \frac{8}{8}$ & $15 \frac{8}{8}$ & 118 & 98 & 268 \\
\hline Word & 08 & 08 & 28 & 148 & $13 \%$ & $16 \frac{8}{8}$ & 218 \\
\hline
\end{tabular}


CHAPTER V

\section{DISCUSSION}

By studying the explanations of "same" and "different" by young children, this study sought to answer four major questions. These questions and the results are discussed below.

1. At what age do children verbally explain similarities and differences?

As was expected, the ability to explain appropriately similarities and differences improved with age. The greatest increase in total test scores occurred between three-years, six-months and six-years, six-months. While the mean scores continued to improve beyond age six-years, six-months, after this point there was a significant decrease in rate of gain in test performance. By six-years, six-months, the mean score on the total test was 16.7 (93 per cent). To answer the question in another way, at five-years, six-months, seven children (70 per cent) answered at least 75 per cent of the items appropriately, and at six-years, six-months nine children ( 90 per cent) answered at least 75 per cent of the items appropriately. The results of this study indicate that by six-years, six-months, most children should be 
able to explain both similarities and differences appropriately the majority of the time. These results confirm a basic assumption in the investigations conducted by Greenfield et al. (1966) and olver and Hornsby (1966). In these investigations the youngest children were six-years to sevenyears in the former and averaged six-years, three-months in the latter, and all children were able to explain similarities and differences.

Contrary to previous reports, this investigation revealed no significant differences at any age between performance on explanations of similarities and explanations of differences. These results do not support the theory that "same" and "different" follow an asymmetric development as do polar adjectives (Fein and Eshleman, 1974), at least not when the task requires a verbal response. Furthermore these results do not support the task sequence presented in the Stanford-Binet Intelligence Scale (Terman and Merrill, 1960) or the Crippled Children's Division (CCD) Manual (CCD, 1958). In these instruments the testee is asked to explain differences at six-years (on both instruments) and similarities at seven-years (Stanford-Binet) and seven-years, sixmonths (CCD Manual). In both instruments, the tasks do not involve visual representations of the items to be compared. On the same type of task in this study, the mean score at five-years, six-months was 70 per cent and at six-years, sixmonths was 95 per cent. 
Wechsler (1967) maintained that it was easier for a child to state attributes separately for each item in a pair than to make one statement about both items. With this observation, he explained that it would be easier for a young child to state differences for two items than to describe one attribute common to both. In the selection of item pairs for this study, items among the similarity pairs were purposely selected to have in common at least one perceptible attribute, at least one common function or related action, and at least one common classification term, so that the frequency of response types corresponding to the three dimension categories could be compared. Because of this careful item selection and in accordance with Wechsler's theory, it should have been easier for a child to explain appropriately similarities on the tasks in this study than on similar tasks not so carefully designed (such as the tasks in the stanfordBinet and the CCD Manual). This may help to explain why younger children in this study were able to perform equally well on Similarity and Difference items.

2. What effect does a change in stimuli have on the appropriateness of the responses?

No significant effect was revealed by a change in the three stimulus types used in this study. At almost every age, performance on the Picture items was slightly better, but not to a significant degree. This result was surprising 
in that performance was expected to decrease with increasing abstractness of the stimuli, from objects to pictures to words without visual referents. Three possible explanations are proposed.

First of all, an order or practice effect might have contributed to the absence of variation in performance. For all subjects, the tasks were presented in the same order beginning with object items, then Picture items, then Word items. This order was agreed upon so as to avoid a failure effect that might have occurred if the most abstract, and assumedly most difficult, task were presented first. Possibly an order or practice effect masked an otherwise increasing level of difficulty in the task-stimuli. Secondly, while the visual stimuli changed, the task, including the verbal stimuli and the response, remained essentially the same. In the other investigations that used objects or pictorial stimuli, the subjects were required to first select the items that were either the same or different. This selection task preceded the verbal task of explaining the similarities or differences between the selected items. Following this procedure, children as young as three-years, seven-months were able to explain differences (Webb et al., 1973) and children at least as young as six-years, six-months were able to explain similarities (Greenfield et al., 1966; Olver and Hornsby, 1966). No children younger than six-years, six-months were included in these two studies. In light of 
the results of the present study, the opportunity to select the items to be compared was probably a more significant factor than the use of different stimulus types in explaining the better performance of the children in the studies mentioned above than the standardization subjects for the stanford-Binet and the CCD Manual.

In line with the above explanation, the third explanation is simply that there may be no significant difference in the performance on tasks using the three stimulus types used in this study. In other words, it might be equally difficult to compare items when the actual items are presented as stimuli, as when pictures of the items are presented, or as when nothing more than the names of the items are presented. If this were true, this would be welcome information to educators who are frequently 1 imited in their resources to supply the actual items under discussion.

3. Do the number and type of properties on which children base their explanations of similarity or difference vary with age?

To answer the first part of the question, the mean number of appropriate responses per item did increase significantly between successive age groups up to six-years, sixmonths. Beyond this age the increases were not significant. Because of the generally poor performance at three-years, six-months, the mean number of appropriate responses per item 
was almost zero (.12). By six-years, six-months, the mean number of appropriate responses per item was about one (1.01) which was all that was necessary to perform the task. Beyond six-years, six-months children tended to supply more appropriate information in response to each item. While the increases between age groups in mean number of responses per item were not significant, a steady increase was apparent. Given ages extending beyond nine-years, six-months, there might have been a significant increase.

In response to the second portion of the question, the results of this study do not support the findings of Greenfield et al. (1966) or Olver and Hornsby (1966). First of all, they found a decrease in the frequency of Type I-Perceptible responses with age. The results of this study reveal a see-sawing fluctuation in frequency of Type I responses. With the exception of the three-years, sixmonths group, I the lowest frequency of Type I responses was at six-years, six-months. The percentage of responses that were Type I increased from 23 per cent at six-years, sixmonths to 44 per cent at eight-years, six-months, then dropped again to 26 per cent at nine-years, six-months. Secondly the previous researchers found a steady increase in Type II-Function responses with age from 49

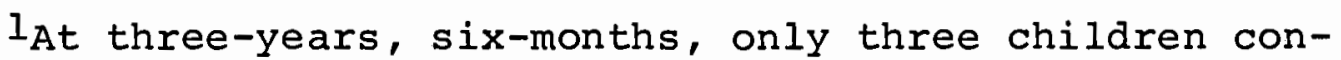
tributed to the appropriate responses, bringing the mean number of items answered appropriately to 2.1 (12 per cent). This low response rate lends poor reliability to any discussion of response type among this age group. 
per cent at six-years to 73 per cent at nine-years. In the present study, there was essentially no change in frequency of Type II responses from six-years to nine-years. In fact there was a slight decrease from 65 per cent at six-years, six-months to 55 per cent at nine-years, six-months. Again with the exception of the three-years, six-months group, the frequency of Type II responses fluctuated gently across all ages, remaining higher than either Type I or Type III responses.

Because of the different age ranges represented in this study and the previous studies, it is difficult to draw more conclusive comparisons. Possibly if the age range in the present study had been extended to include older children, similar trends in the data may have been revealed. Finally, there is always the question as to whether the small population at each age group had a significant effect on the data. The results of this study do support one finding of the previous studies: the frequency of Type III-Nominal responses increased with age and remained lower than both Type $I$ and Type II responses.

No previous study has compared the distribution of response type in explanations of similarity and explanations of difference. This study found that in explaining differences between items, children of all ages referred to function or related action (Type II) much more frequently than they referred to perceptible attributes (Type II); whereas, 
in explaining similarities, they referred to attributes almost as often as function. The most notable difference in response distribution between the two tasks was the frequency of Type III-Nominal responses. While the frequency of Type III responses remained the lowest of the response types, as it increased with age, it increased much faster in explanations of similarity than in explanations of difference.

4. Does the content of the explanations vary as the stimuli vary from (a) actual objects, to (b) pictures, to (c) verbal reference without any visual representation?

No previous study has compared the response distributions on tasks varying in the stimulus types. This study found little evidence to suggest that there may be a significant difference in how children explain differences and similarities on tasks varying in the stimulus types. There were fewer references to perceptible attributes (Type I) when no visual stimuli were presented than when objects or pictures were presented. There were more references to nominal classifications on tasks involving pictures or words than on tasks involving objects. The largest disparity in response type distribution was on tasks involving no visual stimuli. Here there were far more Type II-Function responses than Type I-Perceptible responses. However, overall the dis- 
tribution of the three response types was consistent among the three stimulus types, with a higher percentage of Type II-Function responses and a lower percentage of TYpe IIINominal responses across all ages.

One interesting and unanticipated finding may help to explain the lack of more consistent trends in distribution of response types.

There was a dramatic decrease with age in the number of children in each age group who used the same response type on at least 80 per cent of the items (see Table XXIII). In other words, regardless of the type of responses represented within an age group, a younger child tended to use just one response type consistently. This consistency diminished with age. For instance, at four-years, six-months seven of the nine children who responded appropriately on at least one item used one response type on at least 80 per cent of the items. Three children used Type I-Perceptible responses and four children used Type II-Function responses. This result confirms the finding by Miller and Starzec (1974) that there was

\section{TABIE XXIII}

PERCENTAGE OF CHILDREN IN EACH AGE GROUP WHO USED THE SAME RESPONSE TYPE ON AT LEAST

80 PER CENT OF THE ITEMS

\begin{tabular}{|l|c|c|c|c|c|c|c|}
\hline Age & $3 \frac{1}{2}$ & $4 \frac{1}{2}$ & $5 \frac{1}{2}$ & $6 \frac{1}{2}$ & $7 \frac{1}{2}$ & $8 \frac{1}{2}$ & $9 \frac{1}{2}$ \\
\hline Percentage of S & 1008 & $78 \%$ & $70 \%$ & $50 \%$ & 608 & 208 & $10 \frac{8}{8}$ \\
\hline
\end{tabular}


an increase with age in the type of attributes upon which "same/different" judgments were based. In the present study, there was a higher frequency of Type II responses among the consistent respondents than Type I or Type III responses at al1 ages. At the older ages, an increasing frequency of Type III-Nominal responses for most children made it difficult for a child to reach 80 per cent consistency for one response type.

These results suggest that rather than there being a consistent change in specific response type with age, there is an increase in the number of different response types with age at both the individual level and within the age groups as a whole. In other words, rather than there being an increase or decrease in Type II responses, there may be an increase in the variety of possible response types and consequently a decrease in the frequencies of each separate response type, with the exception of Type III-Nominal responses that appear to increase consistently with age. 
CHAPTER VI

\section{SUMMARY AND IMPLICATIONS}

\section{SUMMARY}

This study investigated the influence of chronological age and stimuli on the explanations of "same" and "different" by young children. Seventy children, between the ages of three-years, six-months and nine-years, six-months, selected on the basis of chronological age, normal speech and language development, and normal verbal maturity, were involved as subjects. A test consisting of a series of verbal tasks was administered to each child. The experimenter recorded and later analyzed and classified all responses for each child, following specific guidelines for judging appropriateness of response and assigning each appropriate response to one of three classifications.

The results of this study revealed that by six-years, six-months most children were able to explain both similarities and differences appropriately. Contrary to previous reports, this study revealed no significant differences between performance on explanations of similarities and explanations of differences. This may have been due in part to the fact that in this study item pairs were carefully selected to be the "same" or "different" with respect to at 
least three dimensions. No significant effect was revealed by a change in the three stimulus types used in this study. This absence of effect supported the argument that the opportunity to select the items to be compared was a more significant factor than a change in stimulus type.

There was a significant increase in mean number of appropriate responses per item up to six-years, six-months. The most frequent response type across all ages was Type IIFunction. The frequency of Type III-Nominal responses increased with age and remained lower than both Type IPerceptible and Type II-Function responses. The frequency of Type III responses increased much faster in explanations of similarity than in explanations of difference. Overall, the distributions of the three response types was consistent among the three stimulus types. The results suggest that rather than there being a consistent change with age in the frequency of specific response types, there is an increase in the variety of different response types with age.

\section{IMPLICATIONS}

\section{Clinical Implications}

The most useful clinical information gained from this study is the observation that stimulus type in itself is not a significant factor influencing performance on a verbal task. On the other hand, the use of visual stimuli in such a way as to alter the task does effect better performance, 
according to the literature. Therefore, when teaching the concepts "same" and "different," a logical task sequence would be (I) a non-verbal grouping task, followed by (2) a combination of grouping and verbal justification of the grouping, followed by (3) a strictly verbal explanation of similarities and/or differences. The intermediate combination task would facilitate performance on the following verbal task. On the strictly verbal task, there would be apparently no advantage in providing visual stimuli.

The results of this study do not reveal any difference in the difficulty of explaining similarities or differences; thus, no logical sequence can be inferred from this study. Conceivably both "same" and "different" could be taught at the same time, especially if the task sequence presented above were followed.

According to the results of this study, explanations based on function or related actions are the most frequent response type to be expected from children of all ages. While a developmental order in the use of different response types is not supported by this study, children may encounter more success comparing objects that are "same" or "different" with respect to function or related action. Reference to nominal classifications in explanations of similarities and differences would be most difficult and logically would be reserved for the final tasks in the program sequence, or could develop out of references to function. 
$\underline{\text { Research Implications }}$

With respect to future research concerning the explanation of similarity and difference, three major modifications are advisable in light of the results of the present study.

First of all, an increase in the number of subjects within each age group would improve the reliability of group performance scores and provide more reliable data on which to base generalizations.

Secondly, the order of the three task-stimuli types should be presented in varied order to subgroups of subjects within each age group in order to safeguard against possible order or practice effects.

Finally, with the age range extended upward well beyond nine-years, six-months, possibly four effects may appear:

1. A resumed increase in the number of appropriate responses per item, or on the other hand,

2. A decrease in the number of appropriate responses per item i.e., limiting reference to one or two essential dimensions;

3. A change in the relative distribution of responses among the three response types, or at least an increasing consistency in percentage of Type IPerceptible and Type II-Functional responses, either an increase, decrease, or plateau;

4. A continued increase in the variety of different 
response types used by an individual on a variety of items.

In addition to the above modifications, it may be of interest to administer the same tasks to an adult population and to investigate the relationship of response patterns to a measure of intelligence or general verbal ability. 


\section{REFERENCES}

Beving, B., and Eblen, R., "Same" and "different" concepts and children's performance on speech sound discrimination. Journal of speech and Hearing Research, 16, 3, $513-517$ (1973).

Blank, M., The Analysis of Cognitive Abilities in the Preschool Age. Bethesal, Md.: ERIC Document Reproduction service, ED 078922 (1972).

Boehm, A., Boehm Test of Basic Concepts. New York: The Psychological Corporation (1971).

Clark, H., The primitive nature of children's relational concepts. In J. Hayes (Ed.), Cognition and the Development of Language. New York: John Wiley and Sons, Inc. (1970).

Crippled Children's Division, University of Oregon Medical School, Manual for Evaluation of Speech, Language, and Hearing Development in Children. Portland, Ore.: University of Oregon Medical School (1958).

Donaldson, M., and Wales, R., On the acquisition of some relational terms. In J. Hayes (Ed.), Cognition and

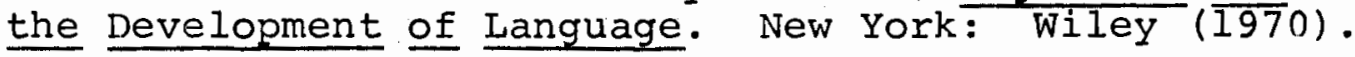

Dunn, L., Peabody Picture Vocabulary Test. Circle Pines, Minn.: American Guidance Service, Inc. (1959).

Fein, G., and Eshleman, S., Individuals and dimensions in children's judgement of same and different. Developmental Psychology, 10, 6,793-796 (1974).

Glucksberg, S., Word versus Sentence Interpretation: Do Adults overextend the Meaning of "Different"? princeton University Research Report No. 16. Bethesda, Ma.: ERIC Document Reproduction Service, ED 112645 (1975).

Greenfield, P., Reich, L., and Olver, R., on culture and equivalence: II. In J. Bruner, R. Olver, and $\mathrm{P}$. Greenfield (Eds.), Studies in Cognitive Growth. New York: John Wiley and Sons, Inc. (1966). 
Ilall, V., Caldwell, E., and Simpson, G., Variahles Affecting the Performance of Young Children on a Letter Discrimination Task. Bethesda, Ma.: FRIC Document Reproduction Service, ED 020797 (1967).

Inhelder, B., and Piaget, J., The Early Growth of Logic in the Child. New York: w. W. Norton and Co. T(1964).

Klatzky, R., Clark, E., and Macken, M., Assymetries in the acquisition of polar adjectives: Iinguistic or conceptual? Journal of Experimental Child Psychology. $16,1,32-\overline{46}(1973)$.

Klausmeier, H., Conceptual Development During the School Years. Bethesda, Md.: ERIC Document Reproduction Service, ED 107374 (1975).

Klausmeier, II., Ghatala, E., and Frayer, D., Conceptual Learning and Development: A Cognitive View. New York: Academic Press (I974).

Maccoby, M., and Modiano, N., on culture and equivalence: I. In J. Bruner, R. Olver, and P. Greenfield (Eds.), Studies in Cognitive Growth. New York: John Wiley and Sons, Inc. (1966).

Mecham, M., Jex, J., and Jones, J., Utah Test of Language Development. Salt Lake City, Utah: Communication Research Associates (1967).

Miller, A., and Starzec, J., The Development of Multidimensional Classification in Children. Bethesda, Md.: ERIC Document Reproduction Service, ED 100525 (1974).

Money, J. (Ed.), The Disabled Reader: Education of the Dyslexic Child. Baltimore: John Fopkins press (1966).

Olver, R., and Hornsby, J., on equivalence. In J. Bruner, R. Olver, and P. Greenfield (Eds.), Studies in Cognitive Growth. New York: John Wiley and Sons, Inc. (1966).

Politzer, R., Auditory Discrimination and the "Disadvantaged:" Deficit or Difference. Bethesda, MI.: ERIC Document Reproduction Service, ED 053126 (1971).

Teaching Resources Corporation, Alike Because Book. Boston: Teaching Resources Corporation (1974).

Terman, L., and Merrill, M., Stanford-Binet Intelligence Scale: Manual for the Third Revision, Form I-M. New

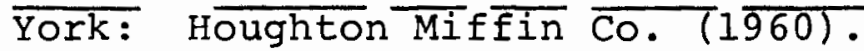


U.S. Department of Commerce. Bureau of the Census. Working Paper iNo. 15: Methodology and scores of Socioeconomic Status (1960).

Vygotsky, L., Thought and Language. Cambridge, Mass.: M. I. T. Press $(\overline{1962})$.

Webb, R., Oliveri, M., and O'Keefe, L., Investigations of the meaning. of "different" in the language of young children. Child Development, 45, 4, 984-991 (1974).

Webb, R., Oliveri, M., and O'Keefe, L., Studies of Young Children's Thought and Language. Final Report. Bethesda, M. : ERIC Document Reproduction Service, ED 082861 (1973).

Wechsler, D., Wechsler Intelligence Scale for ChildrenRevised. New York: The Psychological Corporation (1971).

Wechsler, D., Wechsler Preschool and Primary Scale of Intelligence. New York: The Psychological Corporation (1967).

Wechsler, D., Wechsler Adult Intelligence Scale. New York: The Psychological Corporation (1955).

Wood, B., Children and Communication: Verbal and Non-verbal Language Development. Englewood Cliffs: Prentice Hall (1976). 


\section{APPENDIX A}

LIST OF ITEMS AND DESCRIPTION OF MATERIALS

Task 1: Objects

Difference Items

Item 1. Shoe--hammer: a child's white tennis shoe and a yellow, toy, wooden hammer.

Item 2. Potato--block: a small, red potato and a yellow, wooden block.

Item 3. Knife--sock: a stainless steel, table knife and a child's white sock.

Similarity Items

Item 4. Fork--spoon: stainless steel spoon and salad fork of about equal length.

Item 5. Carrot--orange: plastic carrot and orange.

Item 6. Tow truck--fire engine: metal toys of equal size and color, red.

Task 2: Pictures

All pictures were from the Peabody Language Development Kit, Level \#P.

Difference Items

Item 7. Ball-banana: blue ball with red and white stripes 
and a yellow banana.

Item 8. Elephant--drum: gray elephant and red drum with gold trim and gold sticks.

Item 9. Chair--pants: light brown chair and blue jeans. Similarity Items

Item 10. Cow--horse: light brown cow with white spots and small horns eating grass and a brown horse with white spot on forehead.

Item 11. Tricycle-wagon: red tricycle with black wheels and a red wagon with black tires with yellow hubcaps.

Item 12. Dress--coat: red dress with white trim and red coat with white trim.

Task 3: Words

Difference Items

Item 13. Bird--apple

Item 14. Pencil--bed

Item 15. House--tree

Similarity Items

Item 16. Cat--dog

Item 17. Hat--shirt

Item 18. Cake--cookie 
APPENDIX B

GUIDEIINES FOR JUDGING APPROPRIATENESS

\section{Difference Items}

Accept as appropriate:

1. Parallel comparison, i.e., both statements in the same response category: "You can eat an apple and the bird flies." "A bird has wings and the apple has a peel."

2. Function statement paired with a nominal classification, since function is commonly the basis for nominal classification: "An elephant's an animal and the drum you play with."

3. Statement and denial: "A bira flies and an apple doesn't."

4. Comparative statement: "This is harder than that." "This isn't as big as that."

5. Denial alone: "An apple doesn't fly."

6. List of descriptors when they can be paired as above:

"An apple has a peel, you eat it, it's a fruit.' A bird flies, it can be blue, it's an animal."

Count as inappropriate:

1. Single positive statement about one item that does not state, although it might imply, a denial for the other item: "The bird can fly," (i.e., the apple can't). 
2. Explanation of similarity or any response that does not constitute an explanation of difference.

3. Clearly incorrect response.

4. No response.

Similarity Items

Accept as appropriate:

1. Statement using "they," "them," or "both" to show sameness: "You eat them."

2. Use of conjunction "and" between the two items as the subject or predicate of the statement: "A carrot and an orange are foods."

3. The same statement repeated for each object: "You eat a carrot and you eat an orange."

4. Either of the above even when accompanied by an inappropriate element: "A carrot's a vegetable and an orange's a fruit and you eat them both."

Count as inappropriate:

1. A statement of difference even though a statement of similarity may be embedded: "A carrot grows in the ground and an orange grows in a tree."

2. Any statement that is inaccurate or implausible, except for the substitution of an incorrect color name, shape, category, etc., when the basis for comparison is valid: "A tow truck and a fire truck are both cars."

3. No response. 


\section{APPENDIX $C$ \\ EXAMPLES OF RESPONSE CLASSIFICATION \\ Differences}

Task 1: Objects

Item 1: How are a shoe and a hammer different?

Type I-Perceptible Responses

1. The hammer's white and the shoe's red (age, 4-6).

2. A hammer gots a round thing and a shoe doesn't got a round thing (age, 4-6).

3. Cuz a shoe's not wood (age, 7-6).

\section{Type II-Function Responses}

1. A hammer looks like work on nails and shoes you put on your feet (age, 4-6).

2. You walk on this and you use this to build things (age, 7-6).

3. A shoe you put on your feet and a hammer you hammer nails in (age, 8-6).

\section{Task 2: Pictures}

Item 7: How are a ball and a banana different?

Type III-Nominal Responses

1. A ball is rubber and a banana is food (age, 7-6). 